
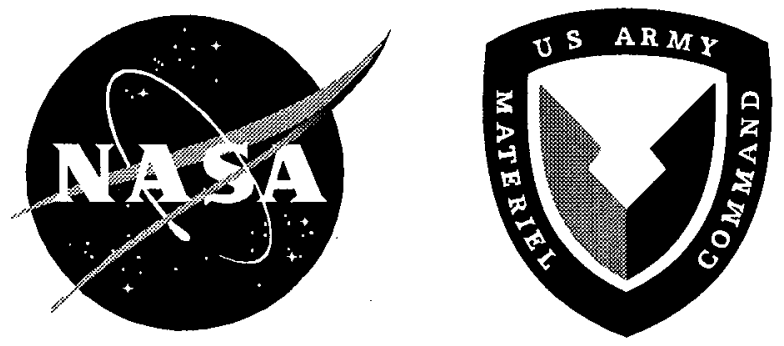

NASA Technical Memorandum 4754 ARL Technical Report 1283 ATCOM Technical Report 97-A-006

\title{
Performance and Vibratory Loads Data From a Wind-Tunnel Test of a Model Helicopter Main- Rotor Blade With a Paddle-Type Tip
}

William T. Yeager, Jr., Kevin W. Noonan, Jeffrey D. Singleton, Matthew L. Wilbur, and Paul H. Mirick 




NASA Technical Memorandum 4754

ARL Technical Report 1283

ATCOM Technical Report 97-A-006

\section{Performance and Vibratory Loads Data From a Wind-Tunnel Test of a Model Helicopter Main- Rotor Blade With a Paddle-Type Tip}

William T. Yeager, Jr.

Vehicle Technology Center

U.S. Army Research Laboratory

Langley Research Center $\bullet$ Hampton, Virginia

Kevin W. Noonan

Joint Research Program Office

Aeroflightdynamics Directorate

U.S. Army Aviation and Troop Command

Langley Research Center $\bullet$ Hampton, Virginia

Jeffrey D. Singleton, Matthew L. Wilbur, and Paul H. Mirick

Vehicle Technology Center

U.S. Army Research Laboratory

Langley Research Center $\bullet$ Hampton, Virginia

National Aeronautics and Space Administration

Langley Research Center $\bullet$ Hampton, Virginia 23681-0001 
Available electronically at the following URL address: http://techreports.larc.nasa.gov/ltrs/ltrs.html

Printed copies available from the following:

NASA Center for AeroSpace Information

800 Elkridge Landing Road

Linthicum Heights, MD 21090-2934

(301) 621-0390
National Technical Information Service (NTIS)

5285 Port Royal Road

Springfield, VA 22161-2171

(703) 487-4650 


\section{Summary}

An investigation was conducted in the Langley Transonic Dynamics Tunnel to obtain data to permit evaluation of paddle-type tip technology for possible use in future U.S. advanced rotor designs. Data were obtained for both a baseline main-rotor blade and a main-rotor blade with a paddle-type tip. The main-rotor blade with the paddle-type tip has the same planform as that developed under the British Experimental Rotor Program (BERP) but uses different airfoils and is referred to in this report as a "BERP-type" blade. The intent of using these two blade sets was to evaluate the effect of the BERP planform geometry on performance and loads, not to conduct an exhaustive study of the BERP concept. The baseline and paddle-type tip blades were compared with regard to rotor performance, oscillatory pitch-link loads, and 4-per-rev vertical fixed-system loads. Data were obtained in hover and forward flight over a nominal range of advance ratios from 0.15 to 0.425 . Results indicate that the paddle-type tip offers no performance improvements in either hover or forward flight. Pitchlink oscillatory loads for the paddle-type tip are higher than for the baseline blade, whereas 4-per-rev vertical fixed-system loads are generally lower.

\section{Introduction}

The next generation of rotorcraft, particularly those used by the U.S. Army, will be required to be faster, more maneuverable and agile, and to carry higher payloads than current generation rotorcraft. To achieve the goals of increased speed, higher load factor, and reduced vibratory loads, designers have continually struggled to obtain the proper combination of airfoils, twist, and planform geometry. Parameters such as advanced airfoils, nonrectangular planforms, static twist, and tip sweep have been investigated (refs. 1 through 5) to determine their effect on rotor performance and efficiency. Conformable rotor concepts (refs. 6 through 13) have also investigated the use of dynamic twist to improve rotor performance and reduce vibratory blade loads.

In 1986, a modified Lynx helicopter equipped with main-rotor blades incorporating a unique paddle-type tip shape claimed the Class E-1 (helicopters without payload) speed record (refs. 14 through 17). The rotor blades used on this Lynx helicopter were developed under the British Experimental Rotor Program (BERP) and thus became known as BERP blades, and the paddle-type tip became known as the BERP tip. Much of the success of the BERP blades in high-speed forward flight has been attributed to the tip shape. On the retreating side of the rotor disk, the BERP tip utilizes vortex flow to delay flow separation in the tip region to attain higher angles of attack than for a rectangular tip before the tip region stalls. The BERP blades also incorporated three advanced airfoil sections, which undoubtedly contributed to the favorable performance improvement over the baseline blades used on the Lynx. The baseline Lynx blades used a RAE 9615 airfoil section in the working region of the blade and over most of the rest of the blade span. The RAE 9615 is a moderately cambered, 11-percent-thick airfoil and its aerodynamic characteristics are a modest improvement over those of the symmetric NACA 0012 airfoil. The BERP blade used a 9-percent-thick cambered airfoil (RAE 9634) in the tip region, an aft-loaded 12-percent-thick airfoil (RAE 9645) in the working region (65-85 percent radius), and a reflexed 12-percentthick airfoil (RAE 9648) in the inboard region. The 9-percent-thick airfoil provides lower drag at high Mach numbers than an NACA 0012 airfoil and about the same maximum lift as the NACA 0012. The aft-loaded airfoil provides about a 35-percent improvement in maximum lift over an NACA 0012 airfoil at the expense of high nose-down pitching moments. The use of a reflexed airfoil with its nose-up pitching moments in the inboard region was necessary to offset the adverse effects of the nose-down pitching moments of the aft-loaded airfoil. No experimental data are currently in the public domain to quantify the contribution that the paddle-type tip made to the performance of the BERP rotor. Because of the success of the BERP blade, it was felt that data should be obtained to permit an evaluation of the paddle-type tip technology for possible use in future U.S. advanced rotor programs.

The data were obtained in the Langley Transonic Dynamics Tunnel in a DuPont Freon 12 atmosphere using Mach and aeroelastically scaled model rotor blades. A set of BERP-type blades were used as well as rectangular planform baseline blades. The designation "BERP-type" is used because the model paddle-type tip blades had the same planform and twist as the full-scale BERP blades but utilized different airfoils. The intent of using these two blade sets was to determine the effect on performance of the BERP planform geometry. Testing was conducted in hover and forward flight at nominal advance ratios from 0.15 to 0.425 . Model lift and drag were varied to simulate changes in vehicle gross weight and propulsive force. The model hover tip Mach number was maintained at 0.628 . The discussion in this report is intended to provide an overview of the data obtained.

\section{Symbols}

The positive directions of forces, angles, and velocities are shown in figure 1.

A

$a$

balance axial force, $1 \mathrm{~b}$

speed of sound, $\mathrm{ft} / \mathrm{sec}$ 


\begin{tabular}{|c|c|}
\hline$C_{D}$ & rotor drag coefficient, $\frac{D}{\rho \pi R^{2}(\Omega R)^{2}}$ \\
\hline$C_{L}$ & rotor lift coefficient, $\frac{L}{\rho \pi R^{2}(\Omega R)^{2}}$ \\
\hline$C_{Q}$ & rotor torque coefficient, $\frac{Q}{\rho \pi R^{3}(\Omega R)^{2}}$ \\
\hline$D$ & rotor drag, $N \sin \alpha_{s}+A \cos \alpha_{s}, \mathrm{lb}$ \\
\hline$d$ & rotor diameter, $\mathrm{ft}$ \\
\hline$E I$ & rotor blade bending stiffness, $1 \mathrm{~b}-\mathrm{ft}^{2}$ \\
\hline $\mathrm{FM}$ & rotor figure of merit, $0.707 \frac{C_{L}}{C_{Q}}$ \\
\hline $\mathrm{FSO}_{4 \mathrm{p}}$ & $\begin{array}{l}\text { normalized 4-per-rev vertical fixed-system } \\
\text { (balance normal force) load }\end{array}$ \\
\hline$f_{D}$ & vehicle equivalent parasite area, $\mathrm{ft}^{2}$ \\
\hline$G J$ & rotor blade torsional stiffness, $\mathrm{lb}-\mathrm{ft}^{2}$ \\
\hline$L$ & rotor lift, $N \cos \alpha_{s}-A \sin \alpha_{s}, \mathrm{lb}$ \\
\hline$M_{T}$ & rotor hover tip Mach number, $\frac{\Omega R}{a}=0.628$ \\
\hline$m$ & $\begin{array}{l}\text { rotor blade section mass per unit length, } \\
\text { slugs/ft }\end{array}$ \\
\hline$N$ & balance normal force, $\mathrm{lb}$ \\
\hline PL HPP & normalized pitch-link half-peak-to-peak load \\
\hline$Q$ & $\begin{array}{l}\text { rotor-shaft torque, measured from balance } \\
\text { yaw moment channel, } \mathrm{ft}-\mathrm{lb}\end{array}$ \\
\hline$R$ & rotor radius, $\mathrm{ft}$ \\
\hline$r$ & $\begin{array}{l}\text { spanwise distance along blade radius mea- } \\
\text { sured from center of rotation, } \mathrm{ft}\end{array}$ \\
\hline$V$ & free-stream velocity, $\mathrm{ft} / \mathrm{sec}$ \\
\hline$z$ & $\begin{array}{l}\text { distance from wind-tunnel floor to rotor hub, } \\
\mathrm{ft}\end{array}$ \\
\hline$\alpha_{s}$ & rotor-shaft angle of attack, deg \\
\hline$\theta$ & $\begin{array}{l}\text { rotor blade collective pitch angle at } \\
\frac{r}{R}=0.75, \text { positive nose up, deg }\end{array}$ \\
\hline$\theta_{1}$ & $\begin{array}{l}\text { twist angle built into rotor blade, positive nose } \\
\text { up relative to blade root end (station } 6.87 \text { in.), } \\
\text { deg (see fig. 4) }\end{array}$ \\
\hline$\mu$ & rotor advance ratio, $\frac{V}{\Omega R}$ \\
\hline$\rho$ & mass density of test medium, slugs $/ \mathrm{ft}^{3}$ \\
\hline$\psi$ & rotor blade azimuth angle, deg \\
\hline$\Omega$ & rotor rotational velocity, $\mathrm{rad} / \mathrm{sec}$ \\
\hline
\end{tabular}

Abbreviation:

RAE Royal Aircraft Establishment

\section{Apparatus and Procedures}

\section{Wind Tunnel}

The testing was conducted in the Langley Transonic Dynamics Tunnel (TDT). A schematic of the tunnel is shown in figure 2. The TDT is a continuous-flow tunnel with a slotted test section and is capable of operation up to Mach 1.2 at stagnation pressures from near vacuum to atmospheric. The tunnel test section is $16 \mathrm{ft}$ square with cropped corners and has a cross-sectional area of $248 \mathrm{ft}^{2}$. Either air or DuPont Freon 12 may be used as a test medium. For this investigation, Freon 12 at a nominal density of $0.006 \mathrm{slugs} / \mathrm{ft}^{3}$ was used as the test medium. Because of its high molecular weight and low speed of sound, the use of Freon 12 aids the matching of modelrotor-scale Reynolds number and Mach number to fullscale values. Since the primary purpose of these tests involved rotor aerodynamic performance, matching fullscale Mach number at Reynolds numbers higher than those obtainable by testing in air was of particular interest. The use of Freon 12 as a test medium also allows the easing of some restrictions on model structural design while still maintaining dynamic similarity. For example, the heavier test medium permits a heavier, less efficient structural design to obtain the required stiffness characteristics and thus eases design and fabrication requirements of the model (ref. 18).

\section{Model Description}

Two sets of model rotor blades with representative Mach and aeroelastic scaling were used during these tests: a set of rectangular planform baseline blades and a set of BERP-type blades. Both sets of blades have the same airfoil distribution, twist distribution, and thrustweighted solidity. The planform geometry and twist distribution of each blade set is shown in figures 3 and 4, respectively. Because the coordinates of the RAE airfoils used on the BERP rotor blades were not available, two state-of-the-art U.S. airfoils were selected for use on these model rotor blades. The BERP blade design philosophy of using an aft-loaded airfoil in the working region of the blade and a reflexed airfoil from inboard of the aftloaded airfoil to the root end was not incorporated in the BERP-type model rotor blades. Each blade used RC(4)-10 and RC(3)-07 airfoils (fig. 3). The 10-percentthick RC(4)-10 airfoil was selected for the inboard region of the blade $(r / R \leq 0.84)$ based on its proven performance (ref. 19) as an inboard airfoil section. The RC(4)-10 airfoil has high maximum lift coefficients at Mach numbers up to 0.5 , very low pitching-moment coefficients over a broad range of Mach numbers and low angles of attack, and moderately high drag divergence Mach numbers at low angles of attack. Initially, the 8-percentthick $\mathrm{RC}(3)-08$ airfoil was selected for the tip region 
$(r / R \geq 0.866)$ because of its proven performance (ref. 20) as a tip airfoil section. The RC(3)-08 airfoil has moderately high maximum lift coefficients at Mach numbers up to 0.5 , very low pitching-moment coefficients over a broad range of Mach numbers and angles of attack, and very high drag divergence Mach numbers at low to moderate angles of attack. However, it was discovered that applying the $\mathrm{RC}(3)-08$ airfoil to this region of the BERP-type blade would result in an increase in the rotor blade thickness with increasing $r / R$, that is, between $r / R=0.84$ and 0.866 , rather than the desired constant thickness or decrease in thickness. Scaling the thickness distribution of the $\mathrm{RC}(3)-08$ so that the maximum thickness was 7 percent chord eliminated this problem. Thus, the RC(3)-07 airfoil was used from $r / R=0.866$ to 1.0. For the BERP-type blade, the RC(3)-07 airfoil was laid out perpendicular to the swept quarter-chord line for $r / R<0.96$ (ref. 17). A smooth transition was made between these two very different airfoil shapes. The area solidity, thrust-weighted solidity, and torqueweighted solidity of the baseline rotor were 0.101 and the same parameters for the BERP-type rotor were 0.096, 0.101 , and 0.102 , respectively. The structural properties of each blade set are similar to those of the advanced blade set described in reference 4 . The nominal values of mass distribution, flapwise stiffness, and torsional stiffness for each blade set are presented in figures 5 through 7. The chordwise stiffness and torsional inertia distributions were not measured for either blade set.

Each blade set was tested by using the aeroelastic rotor experimental system (ARES) testbed shown in figures 8 and 9. The ARES testbed has a streamlined fuselage shape which encloses the rotor controls and drive system. The ARES testbed is powered by a variablefrequency synchronous motor rated at 47-hp output at $12000 \mathrm{rpm}$. The motor is connected to the rotor shaft through a belt-driven two-stage speed reduction system. The ARES testbed rotor blade pitch-control system and rotor-shaft angle of attack are remotely controlled from the wind-tunnel control room. The model rotor-shaft angle of attack is varied by an electrically controlled hydraulic actuator. Blade collective pitch and lateral and longitudinal cyclic pitch are input to the rotor through the swashplate. The swashplate is moved by three hydraulic actuators. The model rotor hub used in this investigation was a four-bladed articulated hub with coincident leadlag and flapping hinges. The hub operated with a measured pitch-flap coupling ratio of 0.5 (flap up, pitch down).

Instrumentation mounted on the ARES model allows continuous displays of model control settings, rotor forces and moments, blade loads, and pitch-link loads. For these tests, one pitch link was instrumented with a strain gauge to measure pitch-link tension and compres- sion loads. Rotor blade flap and lag motions are measured by rotary potentiometers mounted on the rotor hub. Rotor-shaft speed is determined by a magnetic sensor. The rotating blade data are transferred to the fixed system through a 30-channel slip-ring assembly. Rotor forces and moments are measured by a six-component strain-gauge balance mounted below the pylon and drive system. Rotor lift and drag are determined from the measured balance normal and axial forces (fig. 1). Rotor torque is measured by the balance yawing-moment channel. The balance is fixed with respect to the rotor shaft and pitches with the fuselage. Fuselage forces and moments are not transmitted to the balance by design.

\section{Test Procedure}

The purpose of this test was to obtain data to evaluate the effect of the BERP planform on rotor performance and loads. Therefore, data for both the baseline and BERP-type rotors were obtained at the same nominal test conditions defined by $\mu, M_{T}, \alpha_{s}$, and $\theta$. Data were obtained in hover and in forward flight from nominal values of $\mu=0.15$ to 0.425 . In hover $(\mu=0)$, data were obtained at $z / d=0.83$. At each test point in forward flight, the rotor rotational speed and tunnel conditions were adjusted to give the desired values of $M_{T}$ and $\mu$. The ARES testbed was then pitched to the desired $\alpha_{\mathrm{s}}$. Blade collective pitch was changed to obtain variations in rotor lift. To facilitate data acquisition and reduce blade loads, rotor cyclic pitch was used to remove rotor firstharmonic flapping with respect to the rotor shaft at each test point. The maximum obtainable value of $\theta$ at each combination of $\mu$ and $\alpha_{s}$ was determined by either blade or pitch-link loads or ARES testbed drive-system limits.

Model deadweight tares were determined throughout the range of $\alpha_{s}$ with each set of blades installed. Aerodynamic rotor-hub tares were determined throughout the test ranges of $\alpha_{s}$ and $\mu$ at $640 \mathrm{rpm}$ with the blades removed and the blade cuffs set at a pitch angle of $8^{\circ}$. Both deadweight and aerodynamic hub tares have been removed from the data presented herein. The value of the sum of the deadweight and aerodynamic tares in coefficient form for $\mu=0.40$ and $\alpha_{s}=-6^{\circ}$ are $C_{L}=0.000179$, $C_{D}=-0.000275$, and $C_{Q}=0.000020$. These values represent the upper limit of the magnitude of the tares removed from the data. No corrections for tunnel wall effects have been applied to the data, but, as cited in reference 21 , these effects are considered small for the forward-flight conditions presented herein.

\section{Measurement Uncertainty}

The quality of the performance data obtained during this investigation was addressed. Based on a static calibration of the strain-gauge balance used to measure rotor 
lift, drag, and shaft torque, the accuracy of the measurement of these variables is within the following ranges:

$$
\begin{aligned}
& C_{L} \ldots \ldots \ldots \ldots \ldots \ldots \ldots \ldots \ldots .000138 \\
& C_{D} \ldots \ldots \ldots \ldots \ldots \ldots \ldots \ldots \ldots \ldots 0040 \\
& C_{Q} \ldots \ldots \ldots \ldots \ldots \ldots \ldots \pm 0.000016
\end{aligned}
$$

During the test, 717 data points were obtained. Out of this data set, 177 points were repeated at random. The repeated points included data within any particular run (increasing then decreasing $\theta$ for constant $\alpha_{s}$ and $\mu$ ) as well as run-to-run (resetting of all test parameters, i.e., $\theta$, $\alpha_{s}$, and $\mu$ ) repeat points. The average deviation in $C_{L}$, $C_{D}$, and $C_{Q}\left(\Delta C_{L}, \Delta C_{D}\right.$, and $\left.\Delta C_{Q}\right)$ was determined between the originally obtained data points and the repeat data points. The average deviations for constant values of $\mu, \alpha_{s}, \theta$, and zero 1-per-rev flapping with respect to the shaft were determined to be as follows:

Within any particular run:

$$
\begin{aligned}
& \Delta C_{L} \ldots \ldots \ldots \ldots+0.000031 \text { to }-0.000028 \\
& \Delta C_{D} \ldots \ldots \ldots \ldots+0.000009 \text { to }-0.000005 \\
& \Delta C_{Q} \ldots \ldots \ldots \ldots+0.000002 \text { to }-0.000001
\end{aligned}
$$

Run to run:

$$
\begin{aligned}
& \Delta C_{L} \ldots \ldots \ldots \ldots \ldots+0.00013 \text { to }-0.00000 \\
& \Delta C_{D} \ldots \ldots \ldots \ldots+0.000027 \text { to }-0.000020 \\
& \Delta C_{Q} \ldots \ldots \ldots \ldots+0.000016 \text { to }-0.000004
\end{aligned}
$$

\section{Presentation of Results}

The hover and forward-flight rotor performance data obtained during this investigation are presented as combinations of $C_{L}, C_{D}$, and $C_{Q}$. The values of $C_{L}, C_{D}$, and $C_{Q}$ were obtained from the average of 5000 data samples taken at a rate of 1000 data samples/sec with a filter cutoff of $200 \mathrm{~Hz}$. The value of $C_{Q}$ for each forward-flight rotor task, defined by specific values of $C_{L}$ and $C_{D}$, was obtained by plotting $C_{L}$ versus $C_{D}$ and $C_{L}$ versus $C_{Q}$ at each $\mu$ and interpolating (from $C_{D}$ versus $C_{Q}$ plots) for the value of $C_{Q}$ at the desired $C_{L}$ and $C_{D}$. The desired value of $C_{D}$ was obtained by using a full-scale value of $f_{D}$ to first determine $D$ as follows:

$$
D=f_{D}\left(\frac{1}{2} \rho V^{2}\right)
$$

The value of $C_{D}$ was then determined from $D$. The results for $C_{Q}$ versus $\mu$ are presented for representative values of $C_{L}$ and full-scale $f_{D}$ at one value of $M_{T}$. All the $C_{Q}$ values presented fell within the range of the interpolated data in the plots of $C_{D}$ versus $C_{Q}$; that is, no extrapolations were made to obtain any of the $C_{Q}$ values. The value of $M_{T}$ is representative of a density corresponding to a specific combination of geometric altitude and temperature, that is, $4000 \mathrm{ft} / 95^{\circ} \mathrm{F}$.

Loads data presented consist of pitch-link and fixedsystem oscillatory loads. A harmonic analysis is used to reduce ARES rotor and fixed-system loads to magnitude and phase components for each harmonic of 8 per rev and below. Typically, 12 rotor revolutions of data are processed by using a fast Fourier transform (FFT) with checks provided on the signal periodicity and rotor speed. These checks ensure data integrity and allow processing to occur without signal windowing and the associated loss of signal power. Using more than 12 revolutions of data has been shown to produce no increase in the accuracy of results for harmonics of 8 per rev and below; therefore, all data presented herein have been processed by using 12 rotor revolutions of data. Pitch-link loads data are presented as normalized oscillatory (1/2 peak-to-peak) load versus $C_{L}$. Fixed-system loads data are presented as normalized 4-per-rev normal force versus $C_{L}$. The pitch-link and fixed-system loads data are presented for three values of $\mu$ at values of $\alpha_{s}$ representative of what would be required to produce the necessary propulsive force to represent the same fullscale equivalent parasite areas as for the performance data. Thus, the two rotors may not be at the same $C_{D}$. This method of presentation was chosen because the loads data were believed to be too nonlinear to allow interpolation as with the performance data. All pitch-link oscillatory loads were normalized to the largest pitchlink oscillatory load measured on either rotor throughout the speed range tested. All 4-per-rev fixed-system normal forces were normalized to the largest 4-per-rev fixed-system normal force generated by either rotor throughout the test speed range. This normalizing procedure was chosen because neither the fixed system nor the rotating system of the ARES model is a dynamically scaled representation of any existing helicopter. Therefore, scaling measured model data up to full-scale values would not be meaningful. Ground vibration tests of the ARES testbed have shown no dynamic amplification of any of the strain-gauge balance channels at the rotor 4per-rev frequency.

The data are presented in the following order:

Figure

Rotor hover performance............. 10

Rotor forward-flight performance...... 11 and 12

Pitch-link oscillatory loads $\ldots \ldots \ldots \ldots \ldots \ldots 13$

Fixed-system oscillatory loads . . . . . . . . . 14 


\section{Discussion of Results}

The primary purpose of this investigation was to obtain data that would permit an evaluation of any benefits offered by the BERP planform for possible use in future U.S. advanced rotor programs. The forward-flight performance of both the baseline and BERP-type rotors was defined by the $C_{Q}$ required at a given rotor task specified by the parameters $C_{L}, f_{D}, \mu$, and $M_{T}$. The values of $f_{D}$ chosen were intended to be representative of both a utility- and scout-type aircraft.

\section{Rotor Performance}

Figure 10 presents the hover performance of the baseline and BERP-type rotors at $M_{T}=0.628$ and $z / d=0.83$. Figure 10 (a) presents the performance in terms of $C_{L}$ versus $C_{Q}$; figure $10(\mathrm{~b})$ makes a comparison in terms of rotor figure of merit versus $C_{L}$. Two values of $C_{L}$ are of interest in this figure: 0.0081 , which is representative of a UH-60A helicopter at a gross weight of $18500 \mathrm{lb}$ at a density of $4000 \mathrm{ft} / 95^{\circ} \mathrm{F}$, and 0.0086 , which is representative of a scout-type helicopter at a gross weight of $10500 \mathrm{lb}$ at the same density condition. The data indicate that at both 0.0081 (UH-60A) and 0.0086 (scout-type helicopter) the BERP-type rotor requires a higher $C_{Q}$ than the baseline rotor. This trend of a higher required $C_{Q}$ for the BERP-type rotor for a given $C_{L}$ is evident at $C_{L}$ from about 0.0054 up to the maximum value of $C_{L}$ obtained. The figure of merit of the baseline rotor is clearly higher than that for the BERP-type rotor for $C_{L}$ greater than about 0.0052 . The maximum figure of merit of the baseline rotor occurs at a higher value of $C_{L}$ than the corresponding maximum of the BERP-type rotor. The relative inefficiency of the BERP-type rotor is probably caused by an increase in both the induced and profile torque. A higher induced torque for the BERPtype rotor may result from higher inflow angles in the tip region and additional drag caused by vortex flow around the swept tip. A higher profile torque for the BERP-type rotor would be expected because of the increased chord in the tip region.

Figures 11 and 12 show the forward-flight performance of the baseline and BERP-type rotors, in terms of $C_{Q}$ versus $\mu$, for a range of rotor lift coefficients and three values of $f_{D}$ at $M_{T}=0.628$. The value of $f_{D}$ used in figure 11 is representative of a UH-60A helicopter, and the values of $f_{D}$ used in figure 12 are representative of both low-drag and high-drag configurations for a scouttype helicopter. The data in both figures 11 and 12 show that, for the ranges of $C_{L}$ and $f_{D}$ presented, no improvement in forward-flight performance is offered by the BERP-type rotor. The reduced forward-flight performance of the BERP-type rotor is probably caused by the increased profile drag from the paddle-type tip.

\section{Rotor and Fixed-System Loads}

Figure 13 shows the effects of $C_{L}$ on pitch-link oscillatory loads ( $1 / 2$ peak to peak) at three nominal values of $\mu$. The range of rotor-shaft angle of attack presented for each $\mu$ brackets the value of propulsive force required to offset the value of $f_{D}$ used in figures 11 and 12 . The data show that the pitch-link oscillatory loads for the BERPtype rotor are generally higher than those for the baseline rotor as $C_{L}$ is increased, particularly in the $C_{L}$ range of interest $\left(C_{L}=0.007\right.$ to 0.009$)$. The increase in pitch-link oscillatory loads with increasing $C_{L}$ is indicative of an increase in blade torsional activity which is not unexpected because of the large tip area of the BERP planform. Reference 12 has indicated that increased blade torsional activity can contribute to reduced rotor performance, as was noted in the previous section for the BERP-type rotor. Changes in $\alpha_{s}$, representing an increase in $f_{D}$, show no significant increase in the oscillatory pitch-link loads for either rotor. This same trend was found for the rotors discussed in reference 4 .

Figure 14 shows the effect of $C_{L}$ on the 4-per-rev fixed-system normal force for the same values of $\mu$ and $\alpha_{s}$ as used in figure 13. The data show that generally the BERP-type rotor produces lower 4-per-rev fixed-system normal forces than the baseline rotor in the $C_{L}$ range of interest $\left(C_{L}=0.007\right.$ to 0.009$)$. This trend is different from that shown for the pitch-link oscillatory loads (fig. 13) where the BERP-type rotor produced the higher loads. These trends (figs. 13 and 14) indicate different torsional loads characteristics and vertical hub shear characteristics for the baseline and BERP-type rotors. Increasing the rotor shaft tilt, by varying $\alpha_{s}$, generally showed a reduction in the 4-per-rev fixed-system loads for both rotor systems at $\mu=0.25$ and 0.35 . The 4-per-rev fixed-system pitching and rolling moments (not shown) exhibited similar trends as a function of $C_{L}$ for both the baseline and BERP-type rotors with variations in $\mu$ and $\alpha_{s}$ up to $\mu=0.35$. At $\mu=0.35$, the BERP-type rotor was found to have higher values of both 4-per-rev fixedsystem pitching and rolling moments as a function of $C_{L}$.

\section{Conclusions}

An investigation has been conducted in the Langley Transonic Dynamics Tunnel to evaluate differences between the performance and loads characteristics of a rotor using blades with a paddle-type tip and a rectangular planform baseline rotor. The rotor blades utilizing the paddle-type tip are referred to as the "BERP-type" blades since they have the same planform, but different airfoils, as the rotor blades used in the British Experimental Rotor Program (BERP). Data on the BERP-type rotor are of interest to permit an evaluation of the BERP blade planform for possible use in future advanced rotor programs 
in the United States. Based on the data obtained for the test conditions and model configurations investigated, the following conclusions have been reached:

1. When compared with the baseline rotor, the BERP-type rotor offers no performance improvements in either hover or forward flight.

2. Pitch-link oscillatory loads produced by the BERP-type rotor are higher than those produced by the baseline rotor at lift coefficients of interest.

3. The 4-per-rev vertical fixed-system loads produced by the BERP-type rotor are generally lower than those produced by the baseline rotor at lift coefficients of interest.

NASA Langley Research Center

Hampton, VA 23681-0001

January 2, 1997

\section{References}

1. Bingham, Gene J.: The Aerodynamic Influences of Rotor Blade Airfoils, Twist, Taper and Solidity on Hover and Forward Flight Performance. 37th Annual Forum Proceedings, American Helicopter Soc., 1981, pp. 37-50.

2. Berry, John D.: Performance Testing of a Main Rotor System for a Utility Helicopter at 1/4 Scale. NASA TM-83274, AVRADCOM TR 82-B-3, 1982

3. McVeigh, Michael A.; and McHugh, Francis J.: Influence of Tip Shape, Chord, Blade Number, and Airfoil on Advanced Rotor Performance. J. American Helicopter Soc., vol. 29, no. 4 , Oct. 1984 , pp. 55-62.

4. Yeager, William T., Jr.; Mantay, Wayne R.; Wilbur, Matthew L.; Cramer, Robert G., Jr.; and Singleton, Jeffrey D.: WindTunnel Evaluation of an Advanced Main-Rotor Blade Design for a Utility-Class Helicopter. NASA TM-89129, AVSCOM TM 87-B-8, 1987.

5. Kelley, Henry L.: Effect of Planform Taper on Hover Performance of an Advanced AH-64 Model Rotor. NASA TM-89145, AVSCOM TM 87-B-10, 1987.

6. Lemnios, A. Z.; and Smith, A. F.: An Analytical Evaluation of the Controllable Twist Rotor Performance and Dynamic Behavior. USAAMRDL Tech. Rep. 72-16, U.S. Army, May 1972. (Available from DTIC as AD 747 808.)

7. Lemnios, A. Z.; Nettles, William E.; and Howes, H. E.: Full Scale Wind Tunnel Tests of a Controllable Twist Rotor. Proceedings of a Symposium on Rotor Technology, American Helicopter Soc., Aug. 1976.

8. Doman, Glidden S.; Tarzanin, Frank J.; and Shaw, John, Jr.: Investigation of Aeroelastically Adaptive Rotor Systems. Pro- ceedings of a Symposium on Rotor Technology, American Helicopter Soc., Aug. 1976.

9. Blackwell, R. H.; and Merkley, D. J.: The Aeroelastically Conformable Rotor Concept. Preprint No. 78-59, American Helicopter Soc., May 1978.

10. Weller, William H.: Experimental Investigation of Effects of Blade Tip Geometry on Loads and Performance for an Articulated Rotor System. NASA TP-1303, AVRADCOM TR 78-53, 1979.

11. Blackwell, R. H.; Murrill, R. J.; Yeager, W. T., Jr.; and Mirick, P. H.: Wind Tunnel Evaluation of Aeroelastically Conformable Rotors. Preprint No. 80-23, American Helicopter Soc., May 1980.

12. Yeager, William T., Jr.; and Mantay, Wayne R.: Wind-Tunnel Investigation of the Effects of Blade Tip Geometry on the Interaction of Torsional Loads and Performance for an Articulated Helicopter Rotor. NASA TP-1926, AVRADCOM TR 81-B-5, 1981.

13. Mantay, Wayne R.; and Yeager, William T., Jr.: Parametric Tip Effects for Conformable Rotor Applications. NASA TM-85682, AVRADCOM TR 83-B-4, 1983.

14. Lowson, Martin Vincent; St. David, Barton; Hawkings, David Leonard; Byham, Geoffrey Malcolm; Perry, Frederick John; and Denham, Corton: Helicopter Rotor Blades. U.S. Pat. 4,077,741, Mar. 7, 1978.

15. White, R. W.: Developments in UK Rotor Blade Technology. AIAA Aircraft Design, Systems and Technology Meeting, Oct. 1983. (Available as AIAA-83-2525.)

16. Wanstall, Brian: BERP Blades-Key to the $200 \mathrm{kn}$ Helicopter. INTERAVIA, vol. 3, 1986, pp. 322-324.

17. Perry, F. J.: Aerodynamics of the Helicopter World Speed Record. Proceedings of the 43rd Annual Forum of the American Helicopter Society, May 1987, pp. 3-15.

18. Lee, Charles: Weight Considerations in Dynamically Similar Model Rotor Design. SAWE Paper No. 659, May 1968.

19. Noonan, Kevin W.: Aerodynamic Characteristics of Two Rotorcraft Airfoils Designed for Application to the Inboard Region of a Main Rotor Blade. NASA TP-3009, AVSCOM TR-90-B-005, 1990.

20. Bingham, Gene J.; and Noonan, Kevin W.: Two-Dimensional Aerodynamic Characteristics of Three Rotorcraft Airfoils at Mach Numbers From 0.35 to 0.90. NASA TP-2000, AVRADCOM TR 82-B-2, 1982.

21. Mantay, Wayne R.; Yeager, William T., Jr.; Hamouda, M-Nabil; Cramer, Robert G., Jr.; and Langston, Chester W.: Aeroelastic Model Helicopter Rotor Testing in the Langley TDT. NASA TM-86440, USAAVSCOM TM 85-B-5, 1985. 




Figure 1. Notation showing positive directions of forces, angles, and velocities. 




(a) Top view.

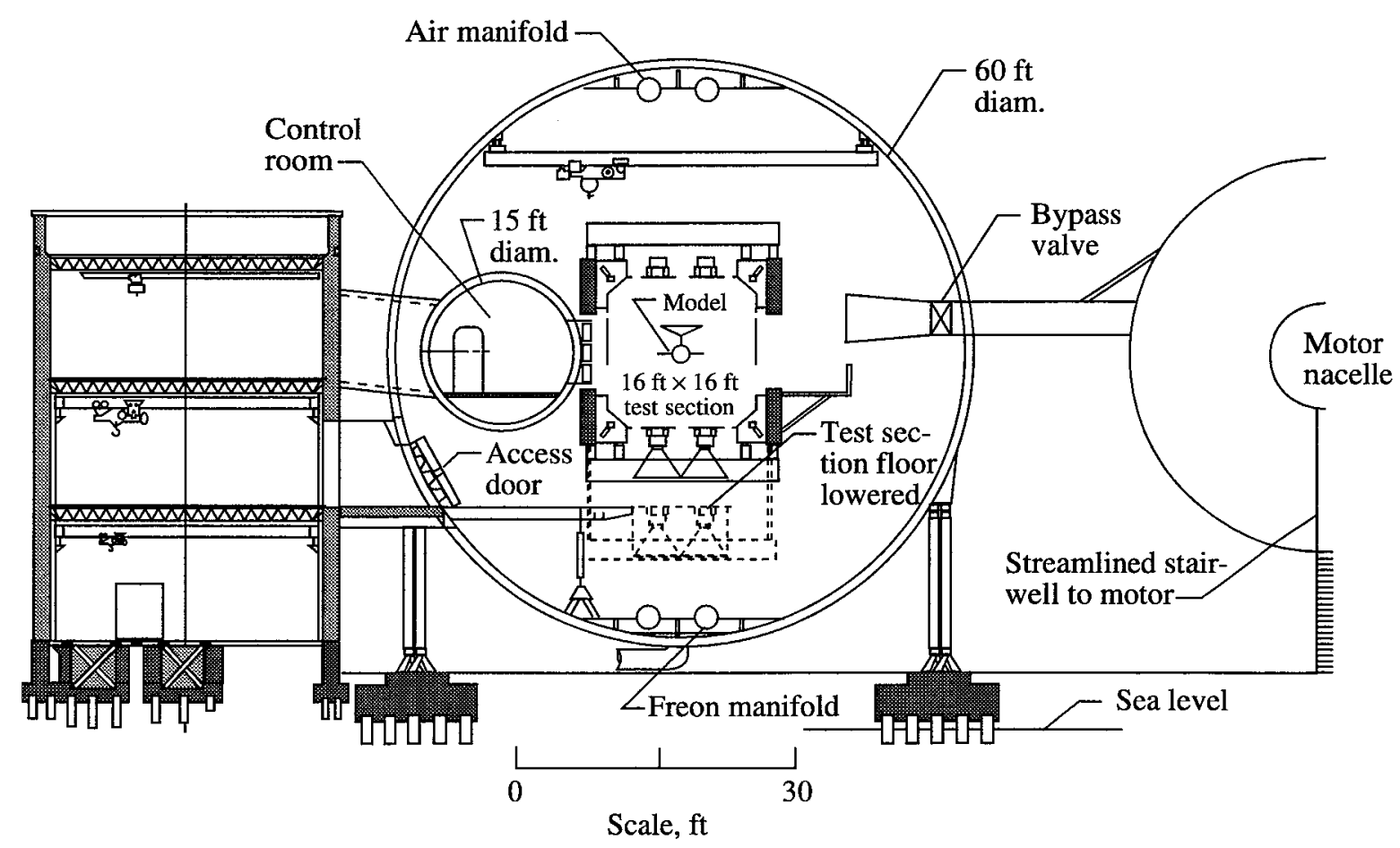

(b) Cross-sectional view.

Figure 2. The Langley Transonic Dynamics Tunnel (TDT). 


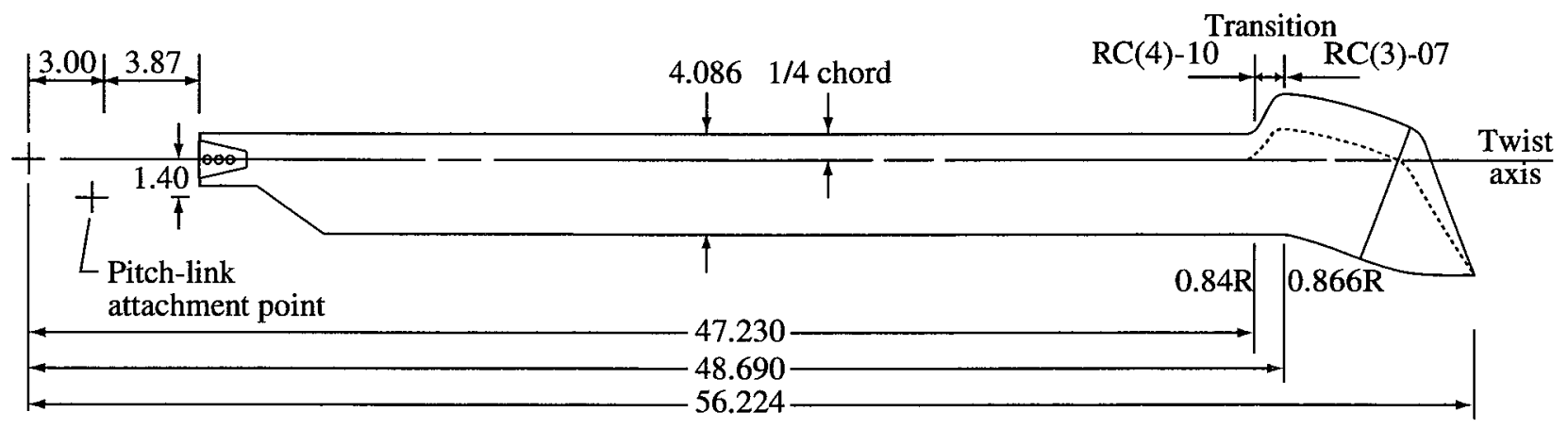

BERP-type rotor blade

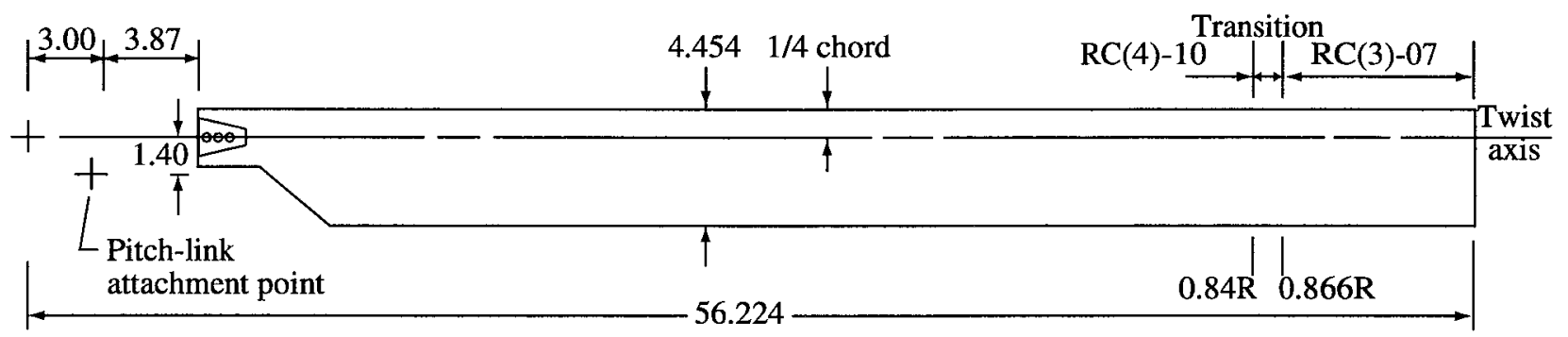

Baseline rotor blade

Figure 3. Rotor blade geometries. Linear dimensions are in inches. 


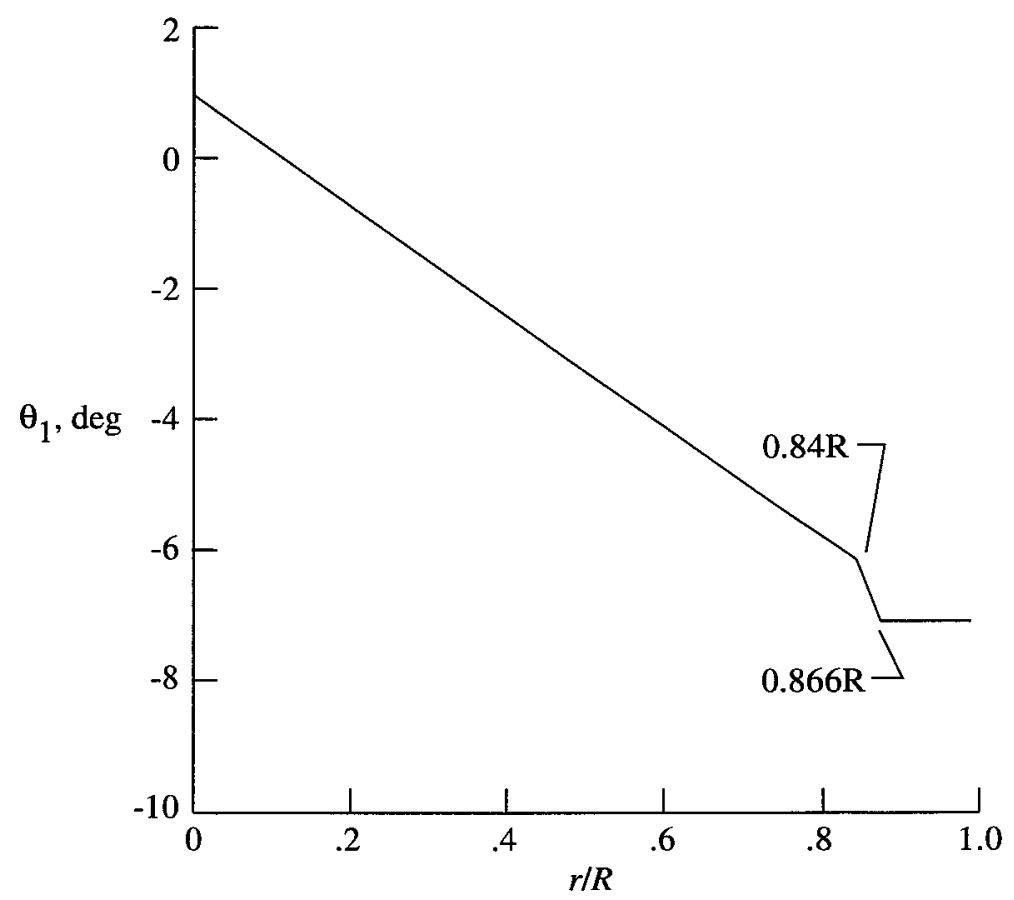

Figure 4. Twist distribution of baseline and BERP-type blades.

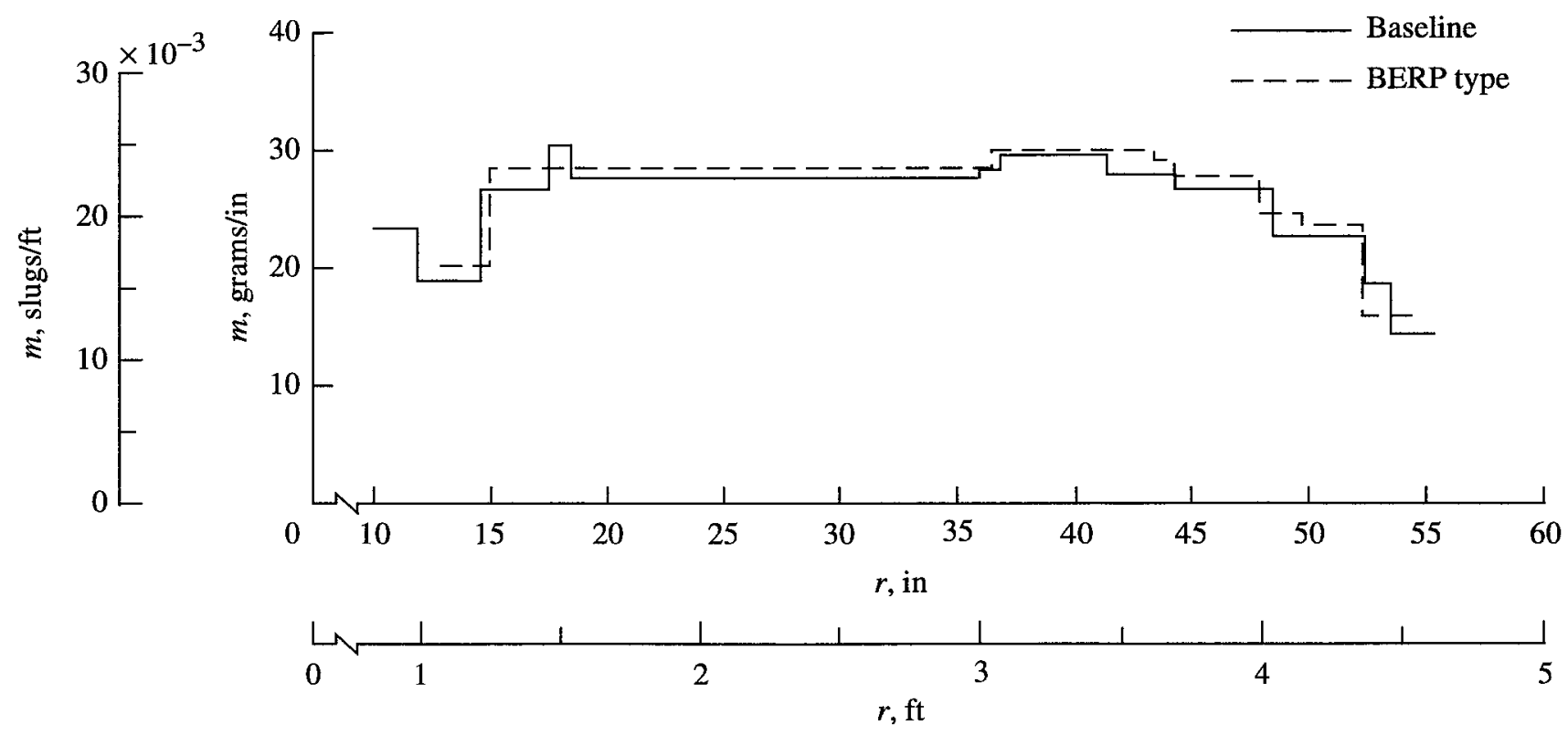

Figure 5. Rotor blade mass distributions (typical). 


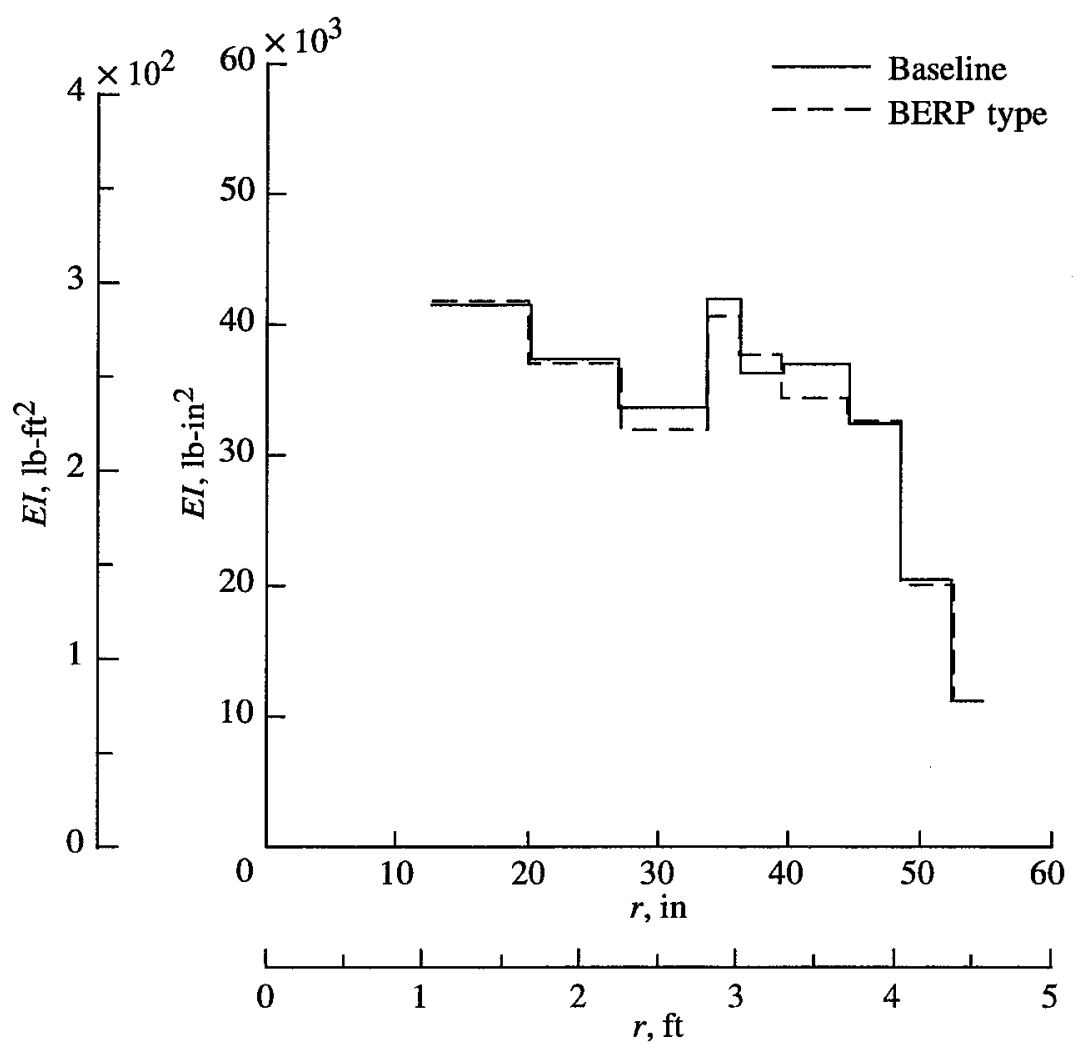

Figure 6. Rotor blade flapwise stiffness distributions (typical).

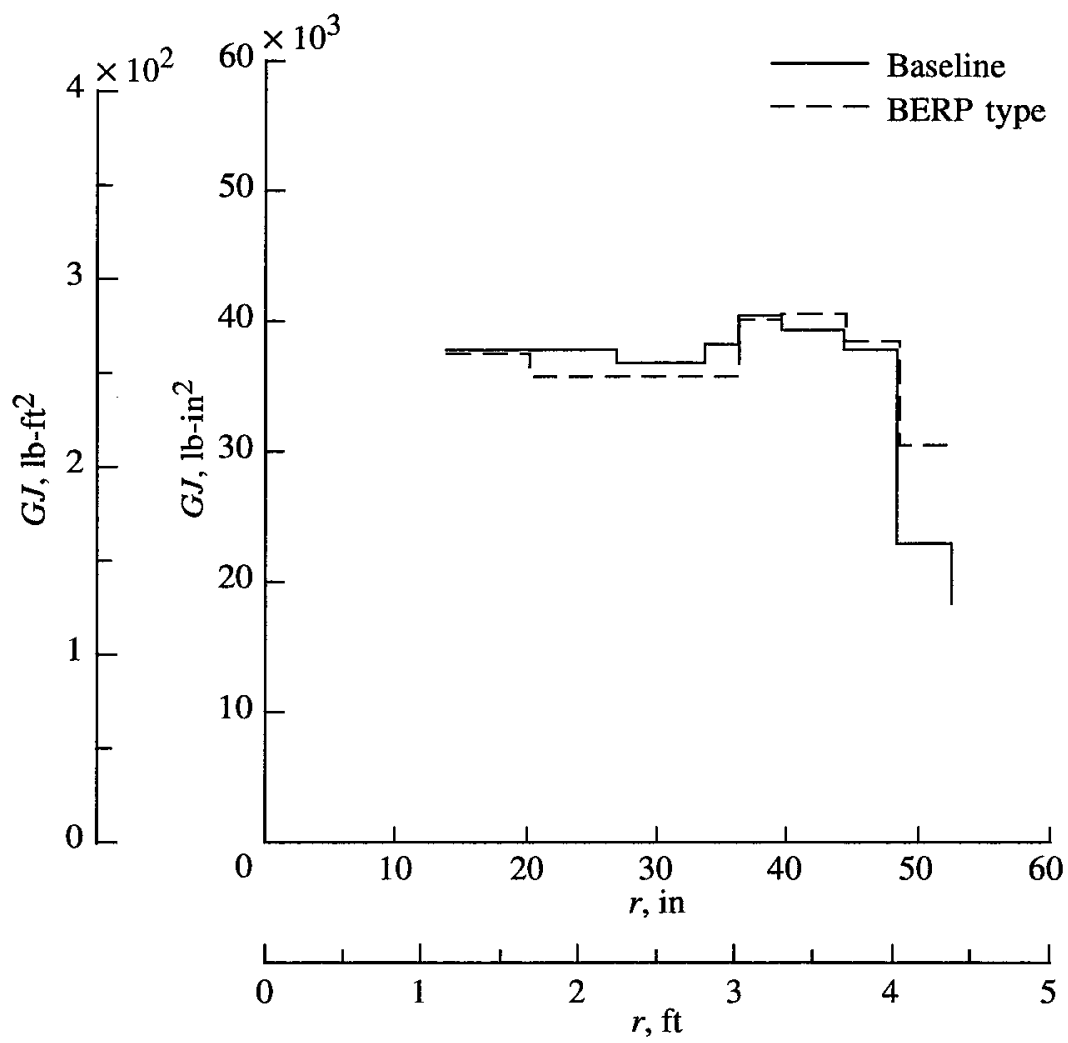

Figure 7. Rotor blade torsional stiffness distributions (typical). 




Figure 8. Aeroelastic rotor experimental system (ARES) model in Langley Transonic Dynamics Tunnel.

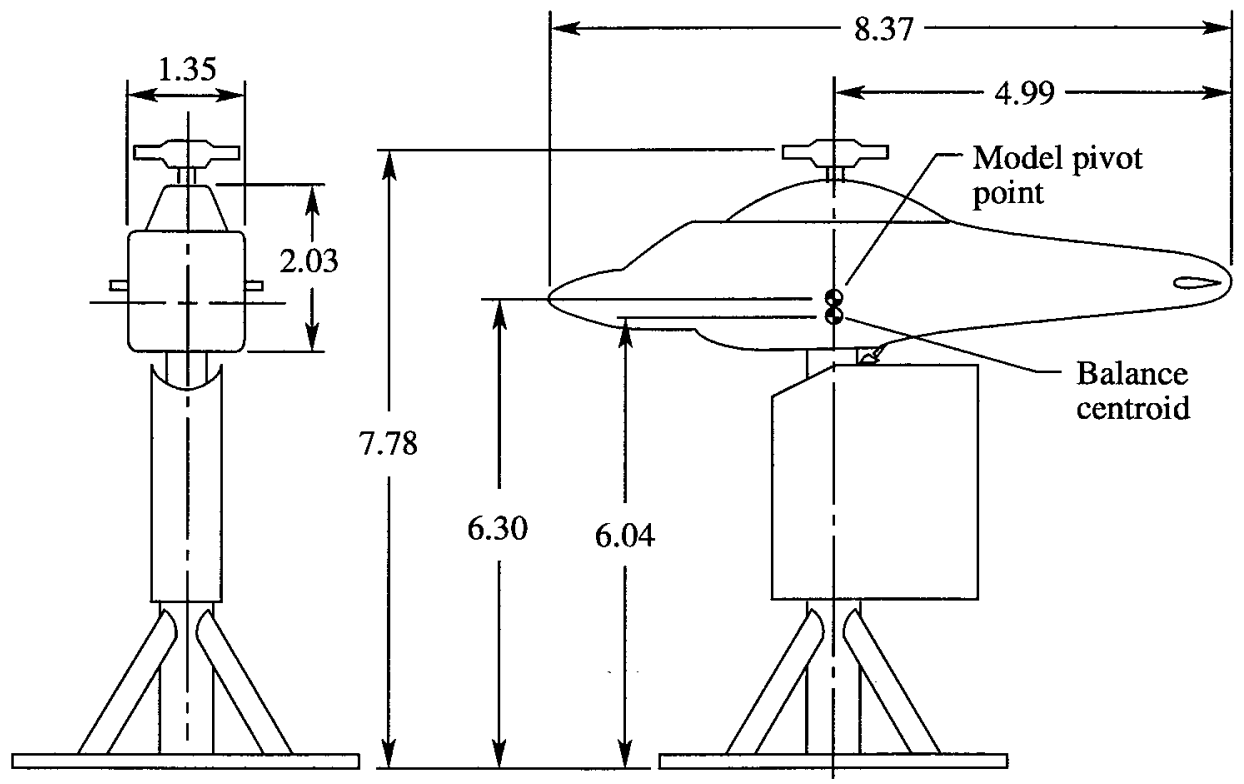

Figure 9. Schematic of aeroelastic rotor experimental system (ARES) model. All dimensions are in feet. 




O Baseline

$\square$ BERP type

(a) $C_{L}$ versus $C_{Q}$.

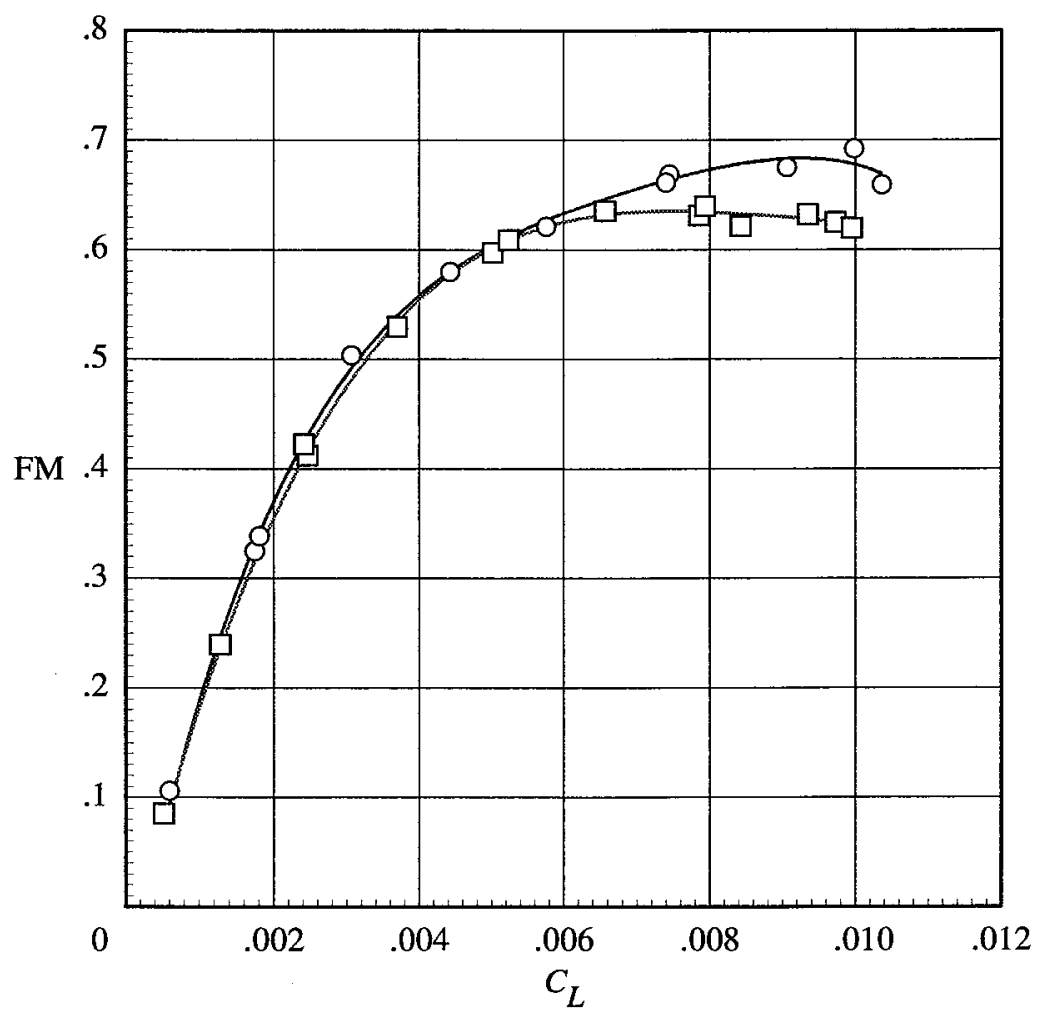

O Baseline

$\square$ BERP type

(b) Figure of merit.

Figure 10. Rotor hover performance at $M_{T}=0.628$ and $z / d=0.83$. 


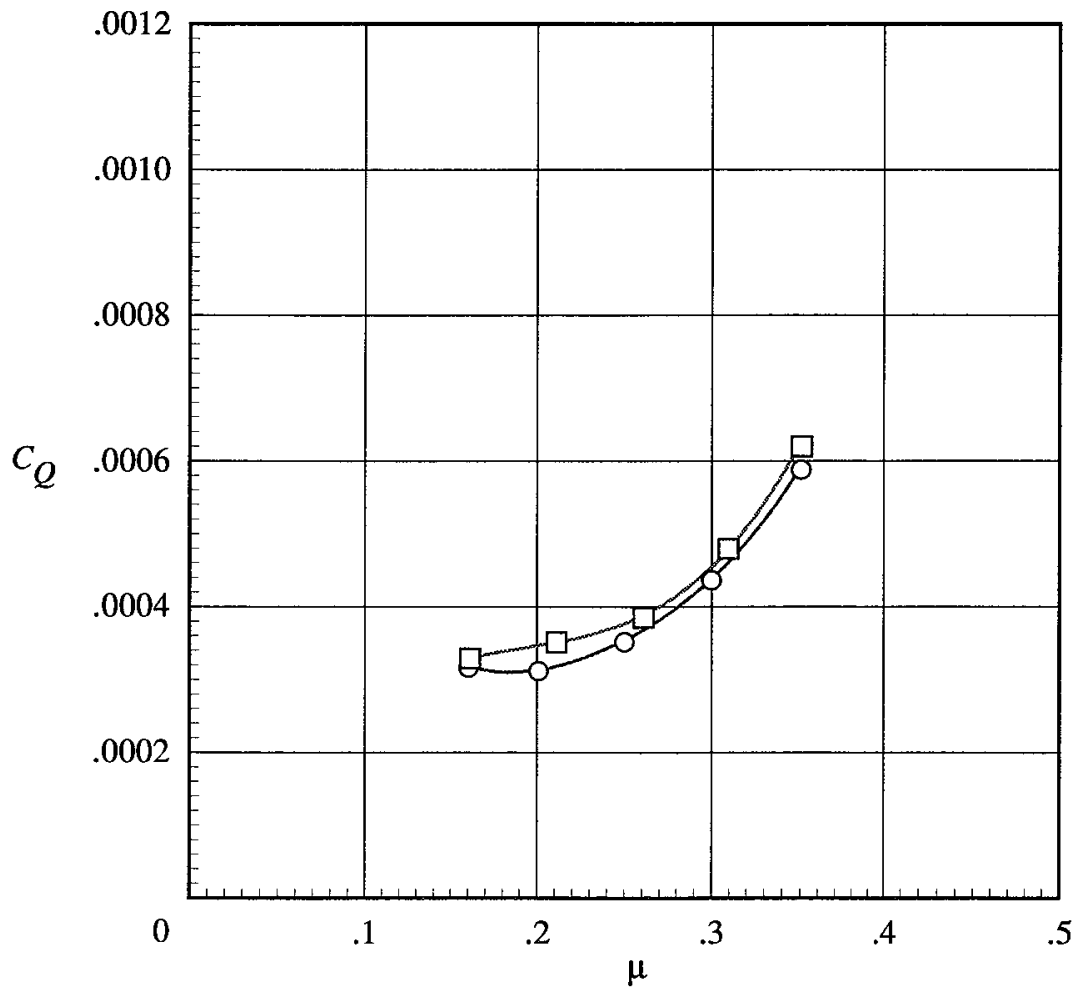

O Baseline $\square$ BERP type

(a) $C_{L}=0.007$.



O Baseline

$\square$ BERP type

(b) $C_{L}=0.0081$.

Figure 11. Variation of rotor torque coefficient with advance ratio for $f_{D}=29.94 \mathrm{ft}^{2}$ and $M_{T}=0.628$. 


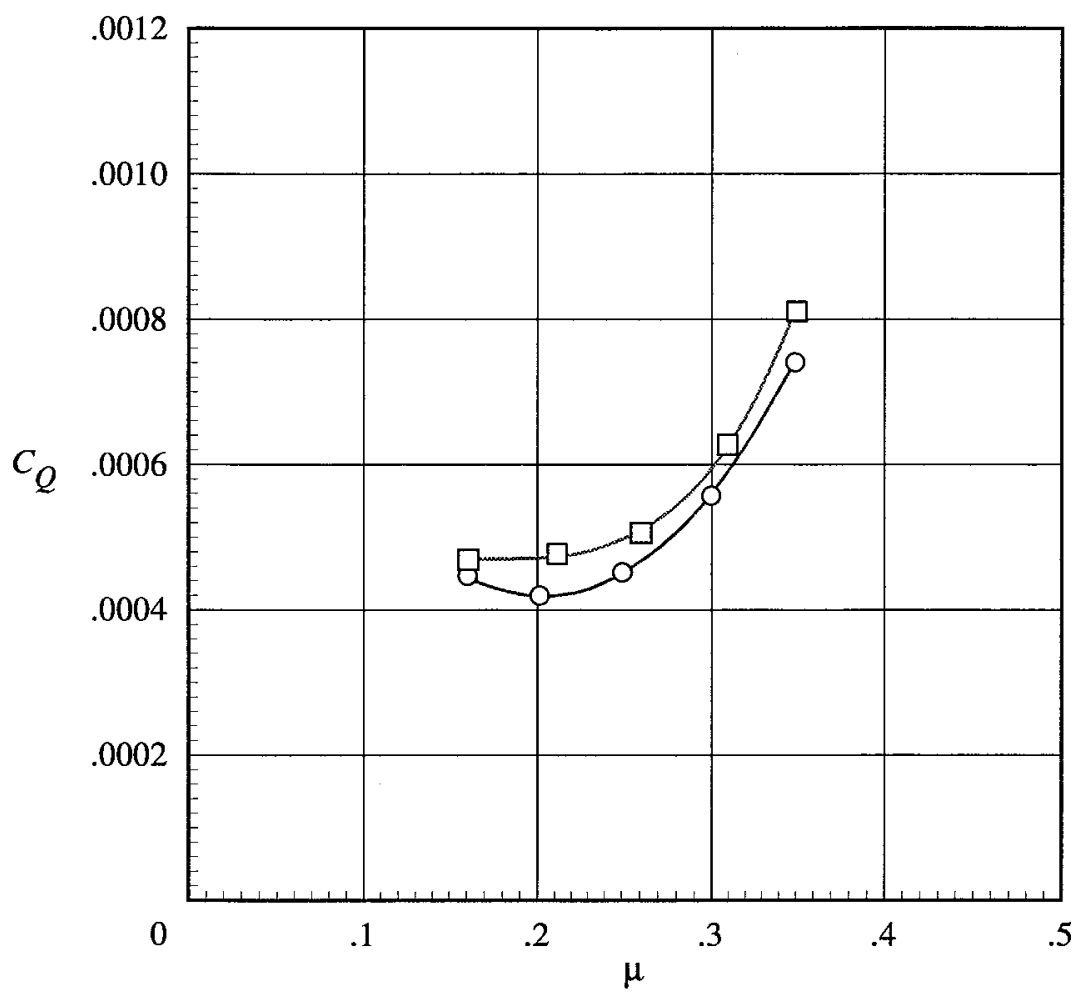

O Baseline

$\square$ BERP type

(c) $C_{L}=0.009$.

Figure 11. Concluded. 


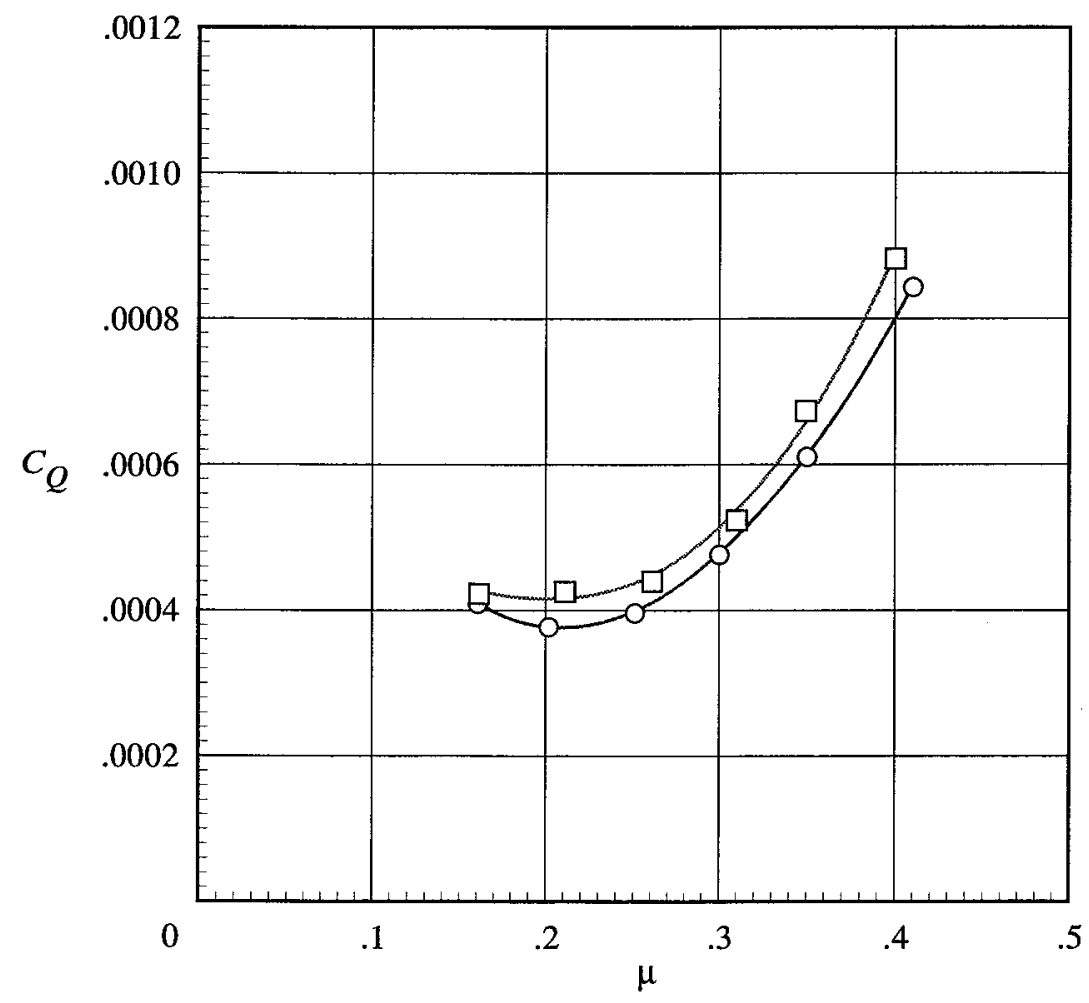

O Baseline

$\square$ BERP type

(a) $C_{L}=0.0086 ; f_{D}=12.0 \mathrm{ft}^{2}$.

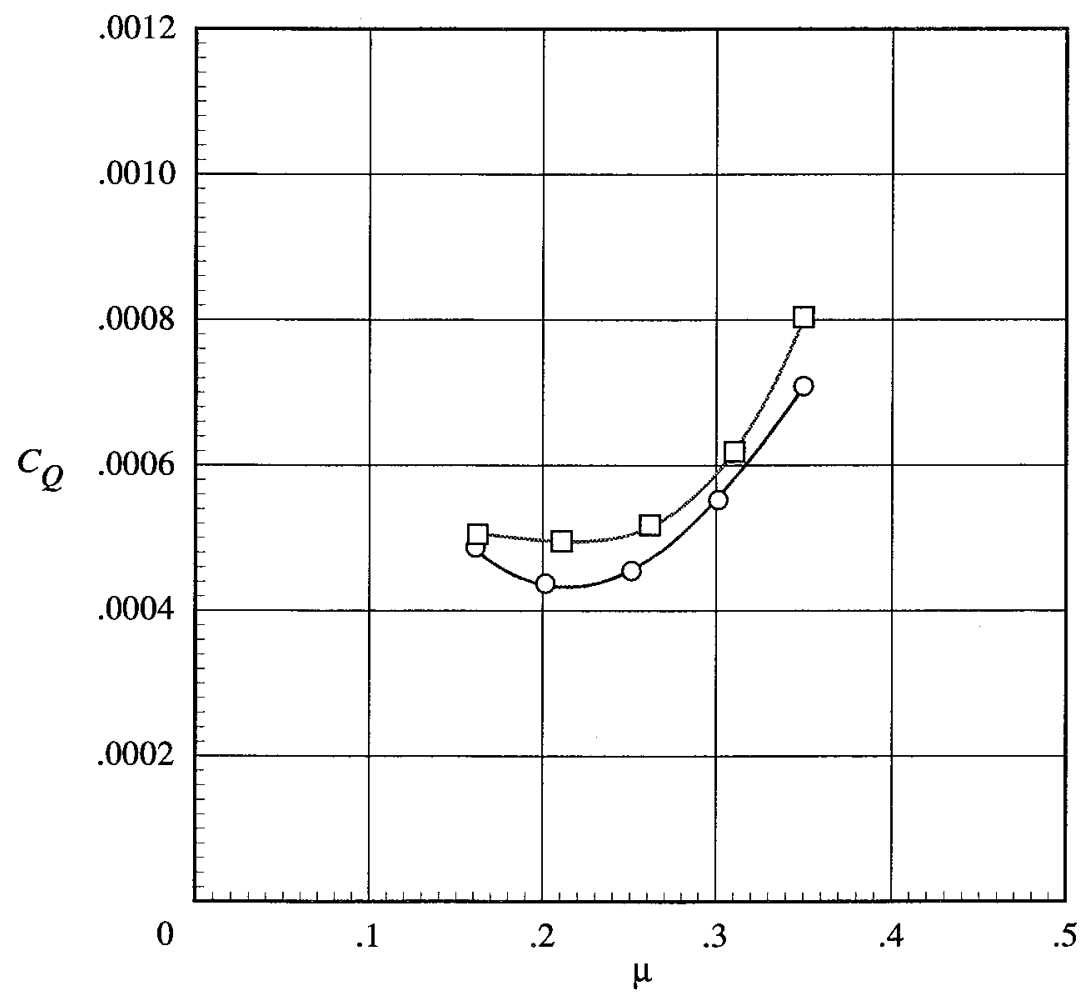

O Baseline $\square$ BERP type

(b) $C_{L}=0.0095 ; f_{D}=12.0 \mathrm{ft}^{2}$.

Figure 12. Variation of rotor torque coefficient with advance ratio for $M_{T}=0.628$. 


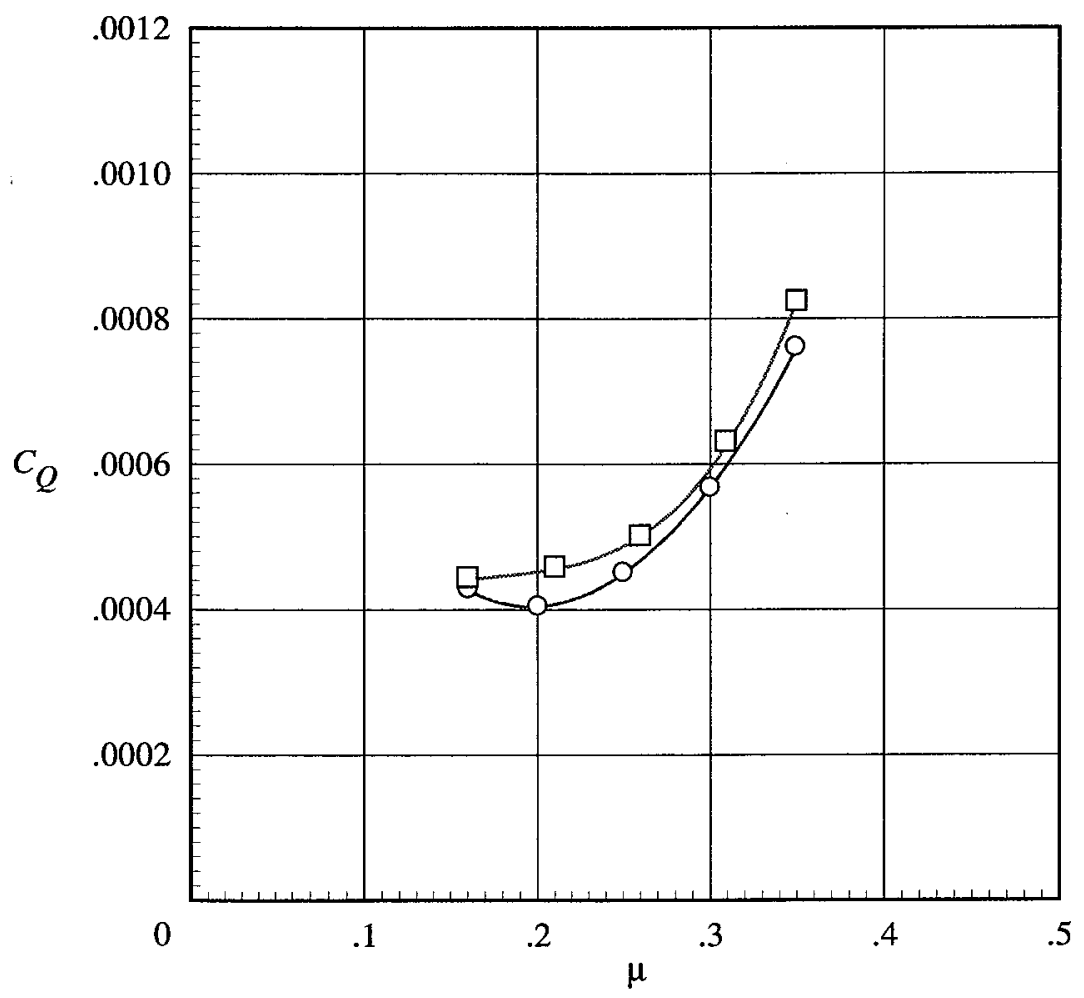

O Baseline

$\square$ BERP type

(c) $C_{L}=0.0086 ; f_{D}=18.5 \mathrm{ft}^{2}$.

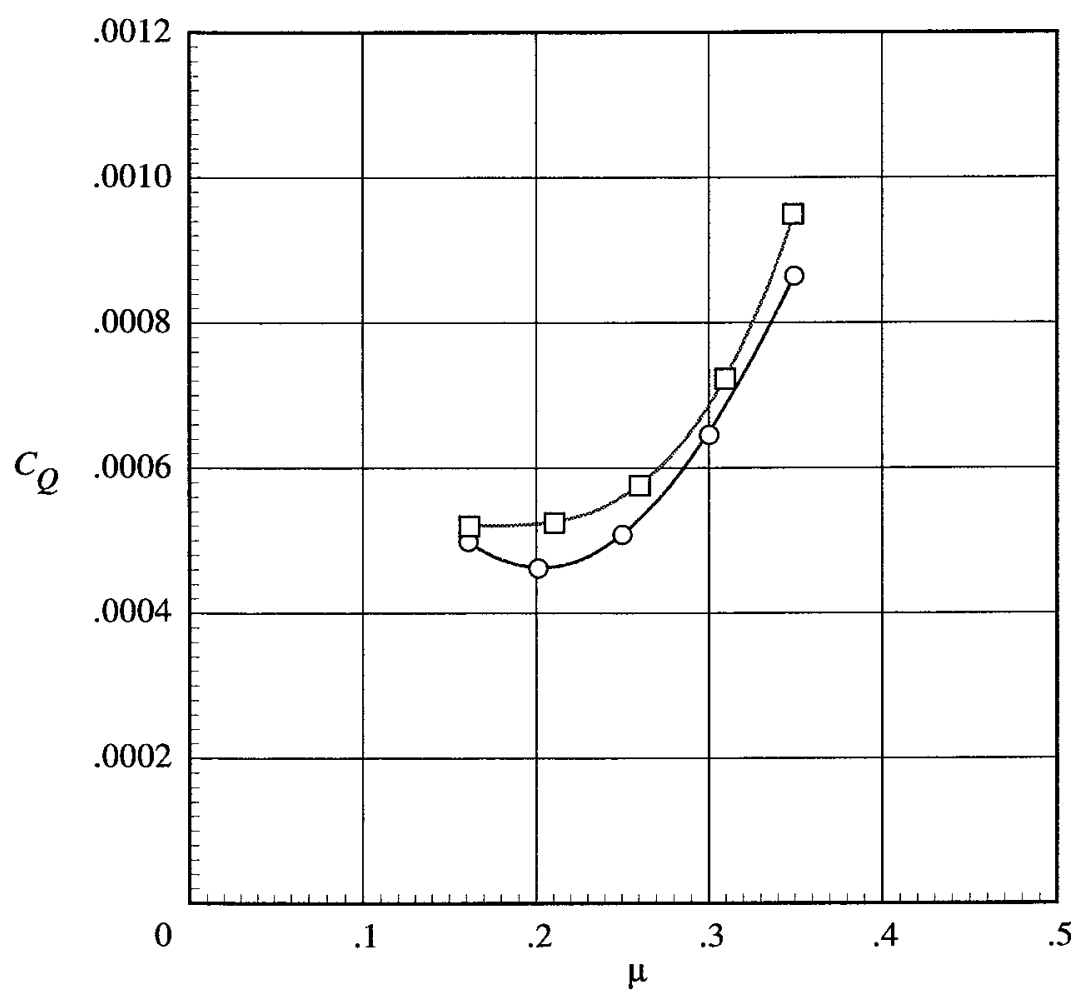

O Baseline

$\square$ BERP type

(d) $C_{L}=0.0095 ; f_{D}=18.5 \mathrm{ft}^{2}$.

Figure 12. Concluded. 


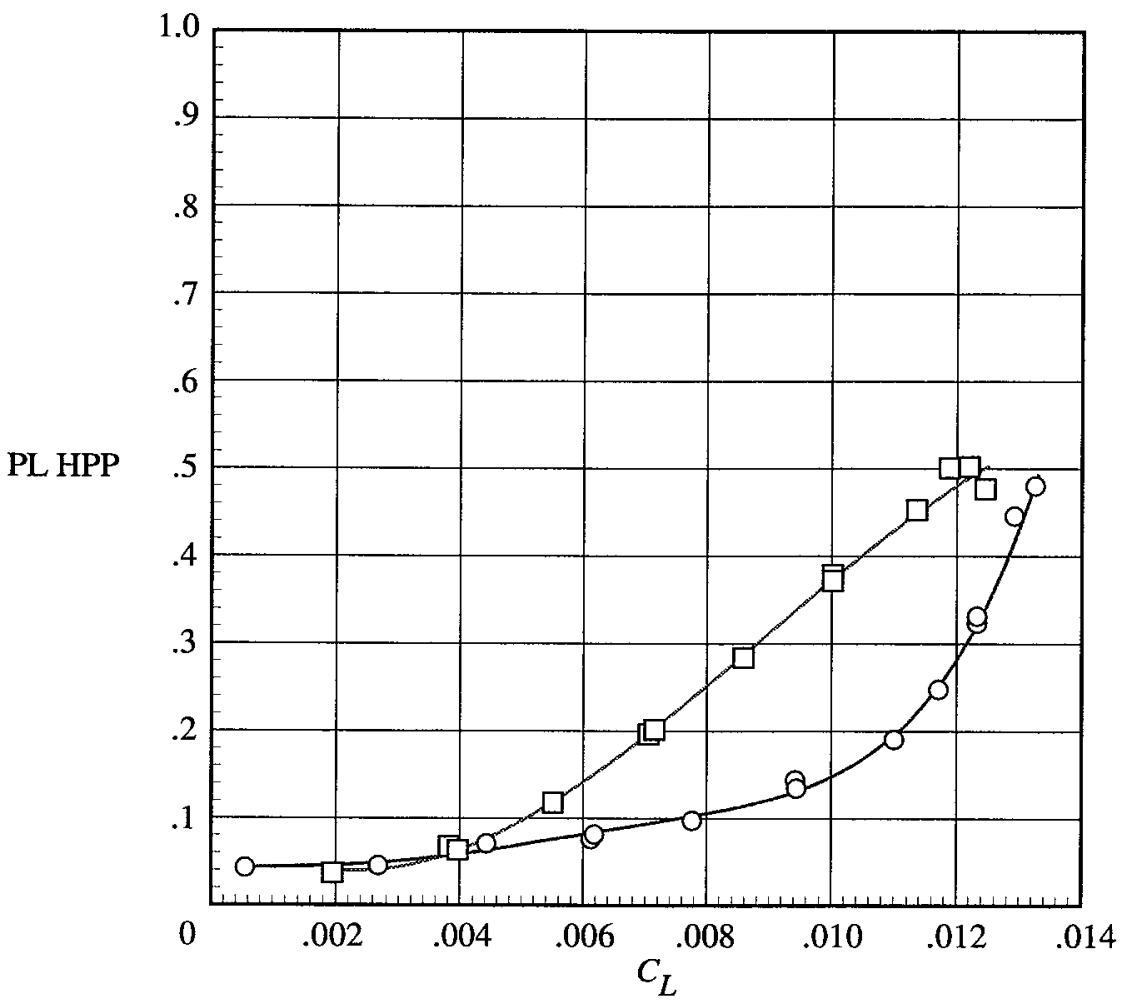

O Baseline; $\mu=0.16$

$\square$ BERP type; $\mu=0.16$

(a) $\alpha_{s}=0^{\circ} ; \mu=0.16$.

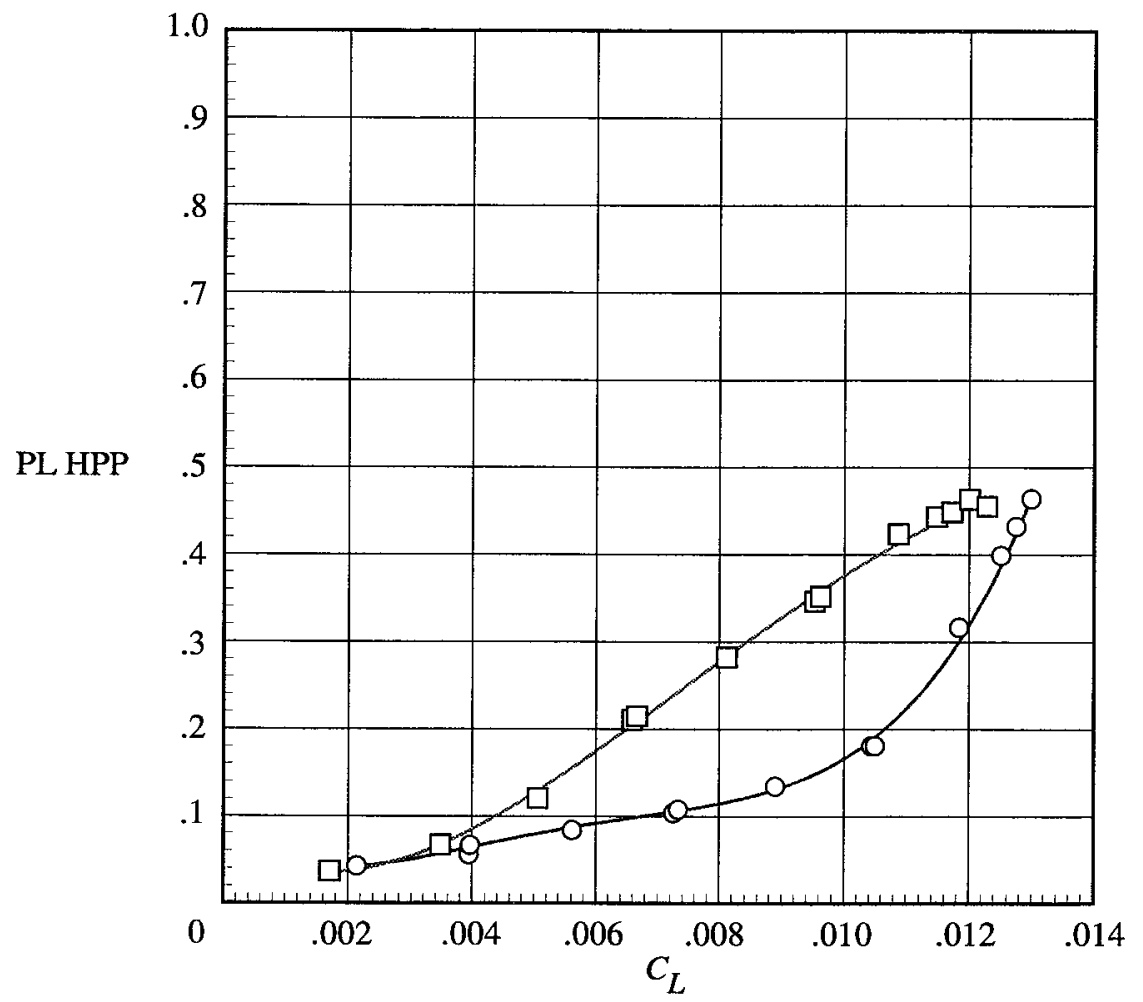

O Baseline; $\mu=0.16$

$\square$ BERP type; $\mu=0.16$

(b) $\alpha_{s}=-2^{\circ} ; \mu=0.16$.

Figure 13. Pitch-link oscillatory loads for baseline- and BERP-type rotors. 


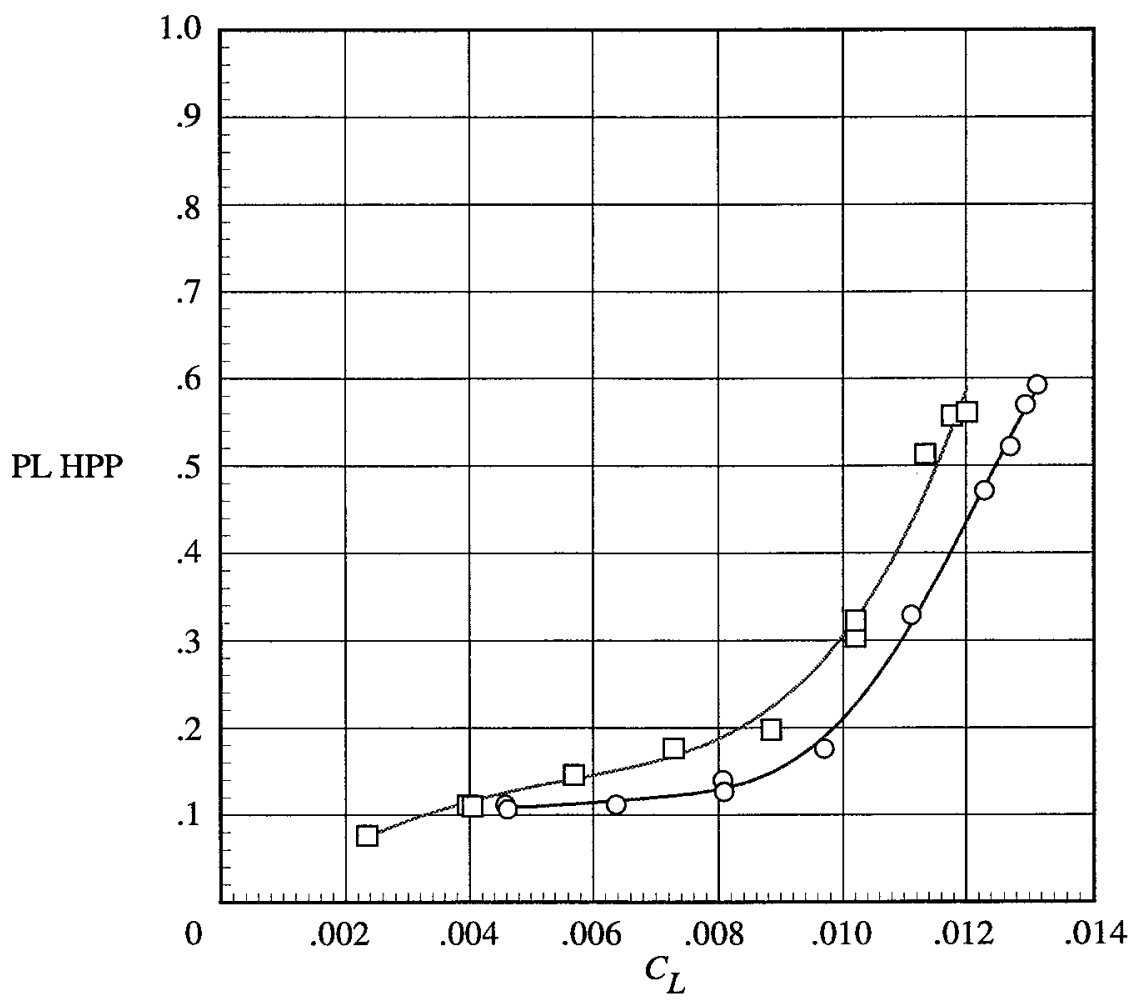

O Baseline; $\mu=0.25$

$\square$ BERP type; $\mu=0.26$

(c) $\alpha_{s}=0^{\circ} ; \mu=0.25$ and 0.26 .

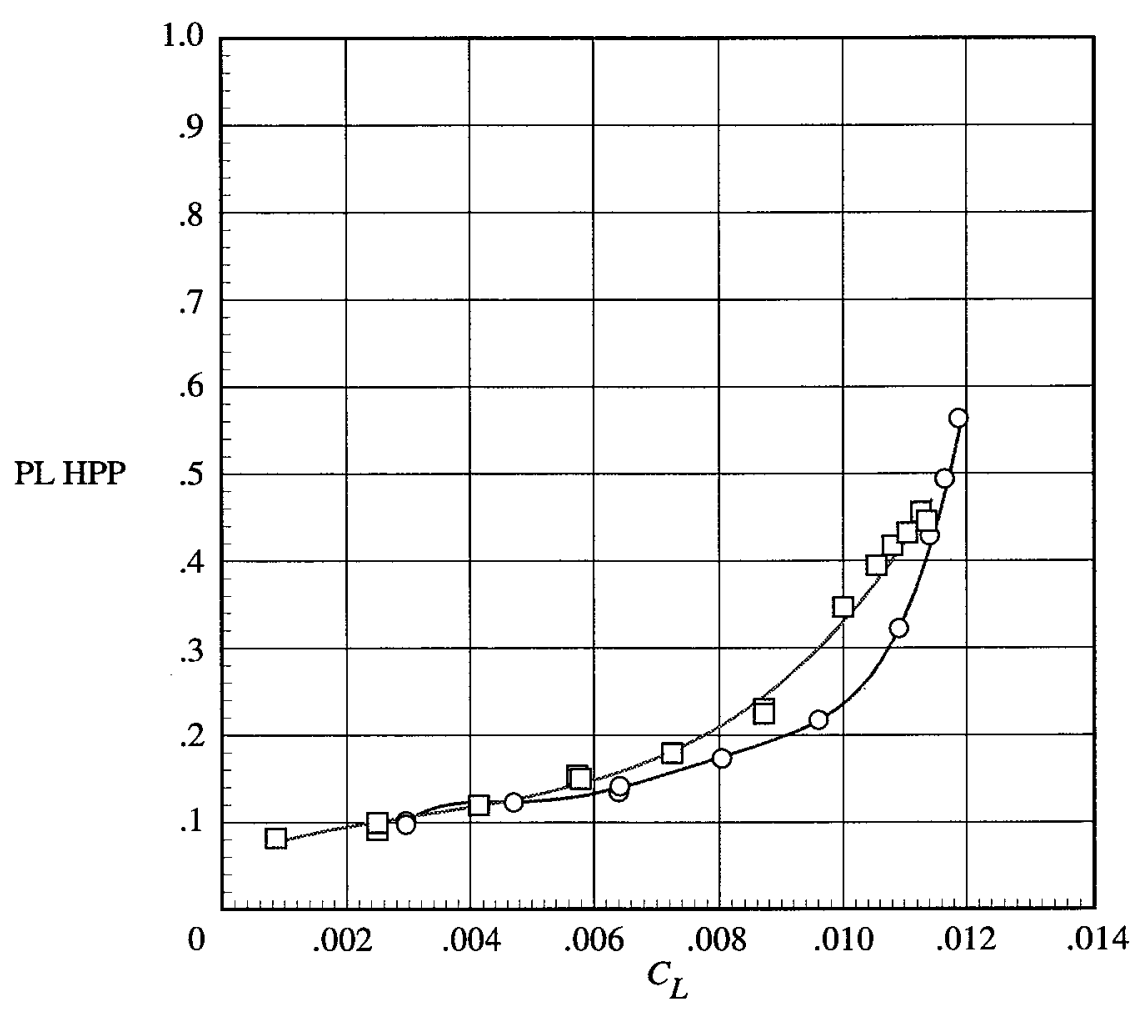

O Baseline; $\mu=0.25$

$\square$ BERP type; $\mu=0.26$

(d) $\alpha_{s}=-4^{\circ} ; \mu=0.25$ and 0.26 .

Figure 13. Continued. 


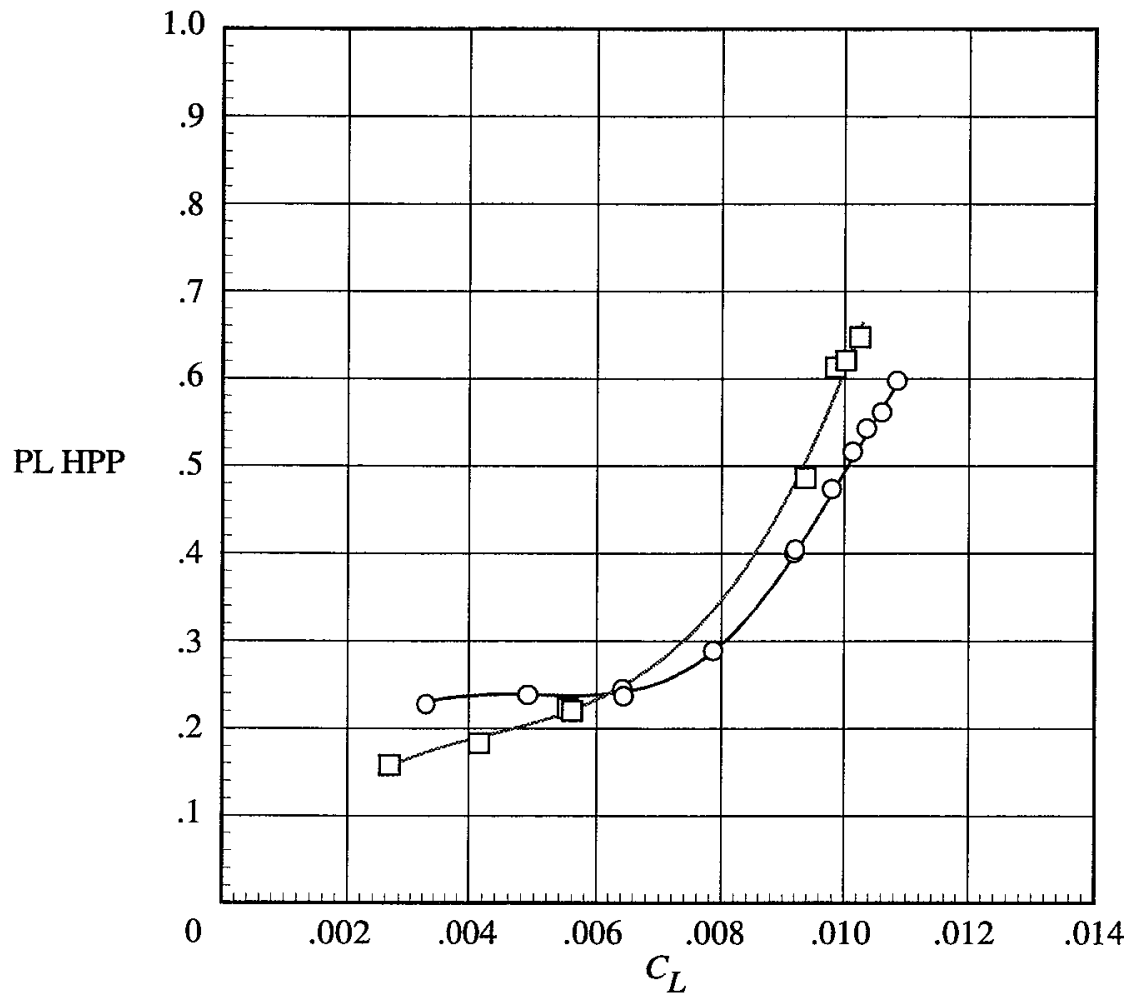

(e) $\alpha_{s}=-2^{\circ} ; \mu=0.35$ and 0.36 .

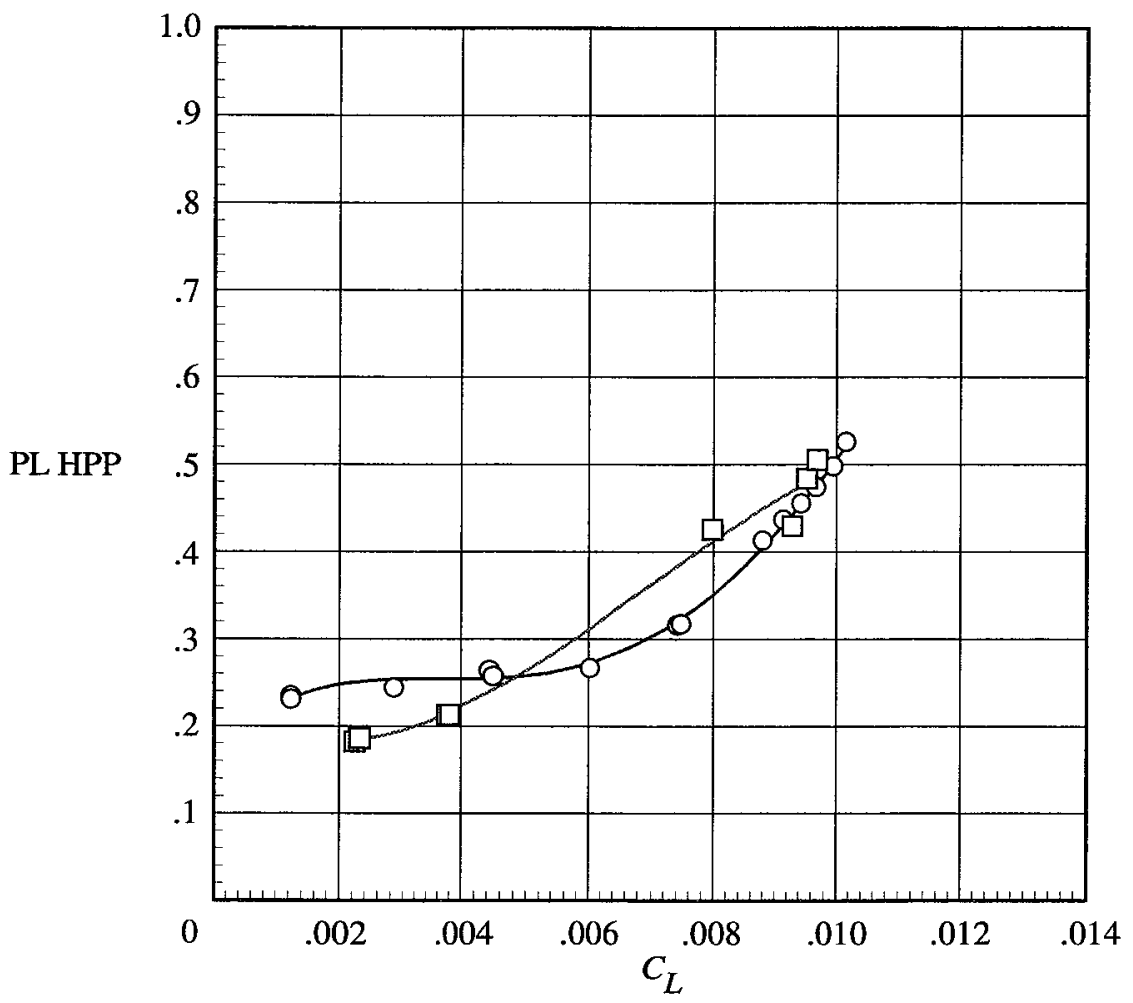

(f) $\alpha_{s}=-6^{\circ} ; \mu=0.35$.

Figure 13. Concluded.
O Baseline; $\mu=0.35$

$\square$ BERP type; $\mu=0.36$
O Baseline; $\mu=0.35$

$\square$ BERP type; $\mu=0.35$ 


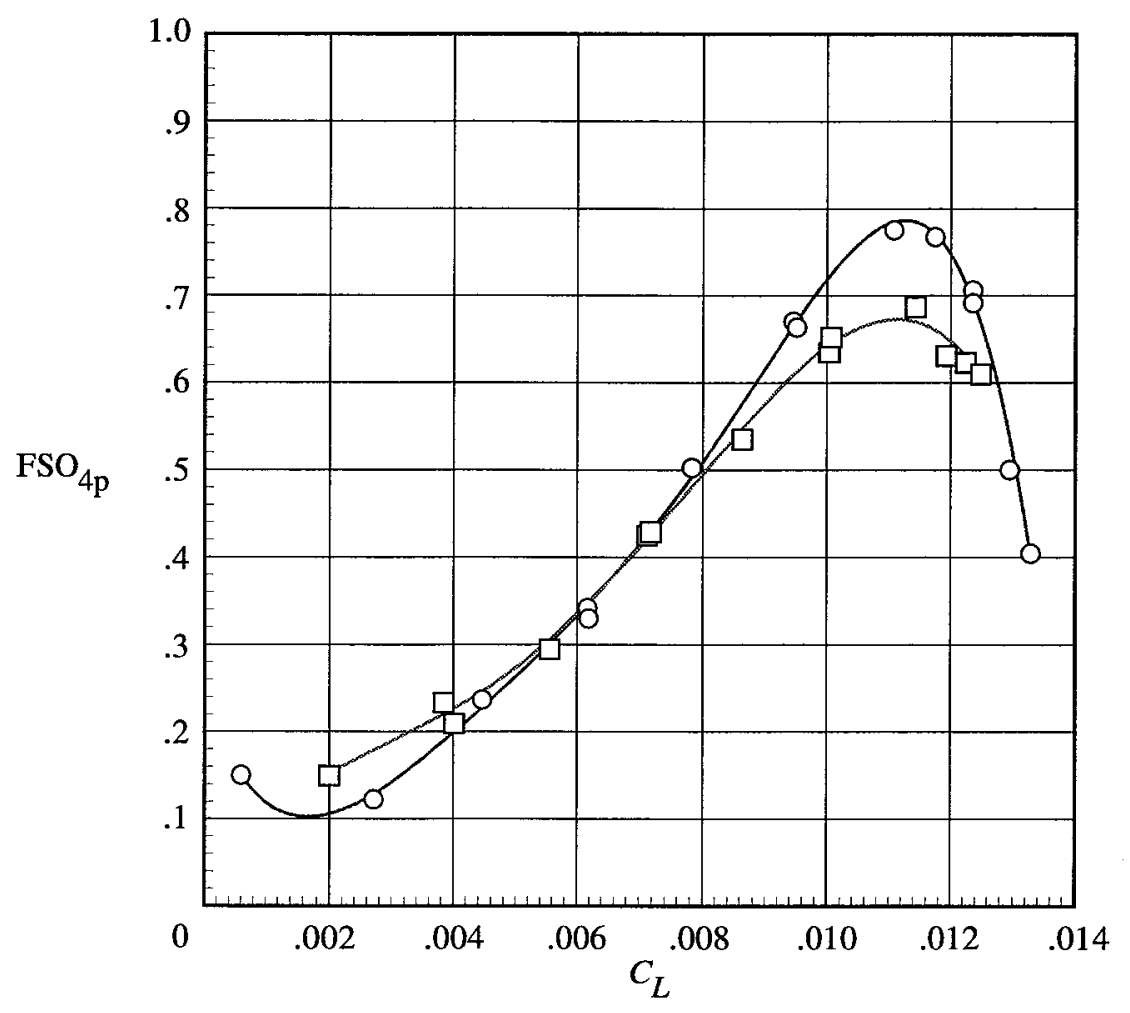

O Baseline; $\mu=0.16$

$\square$ BERP type; $\mu=0.16$

(a) $\alpha_{s}=0^{\circ} ; \mu=0.16$.

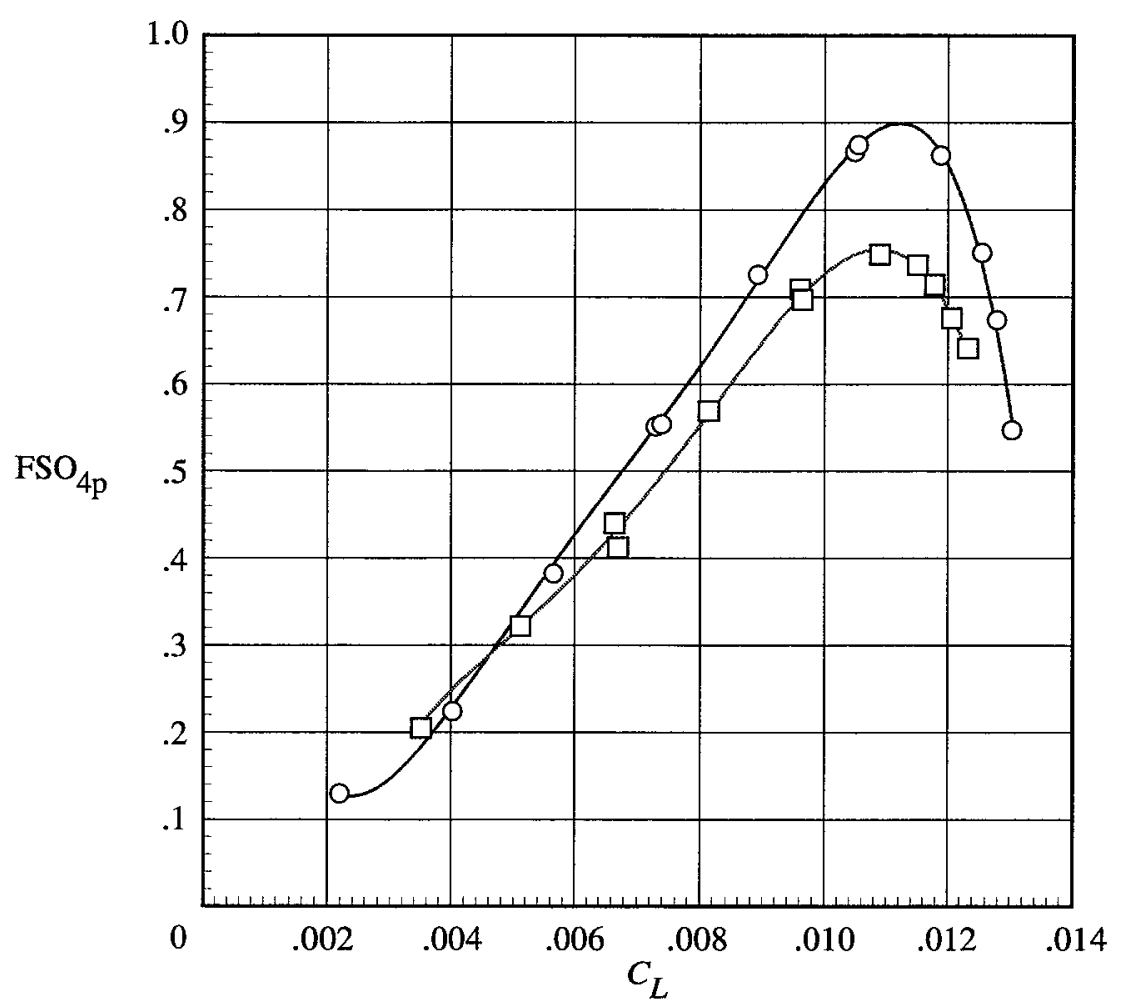

O Baseline; $\mu=0.16$

$\square$ BERP type; $\mu=0.16$

(b) $\alpha_{s}=-2^{\circ} ; \mu=0.16$.

Figure 14. The 4-per-rev fixed-system loads for baseline- and BERP-type rotors. 


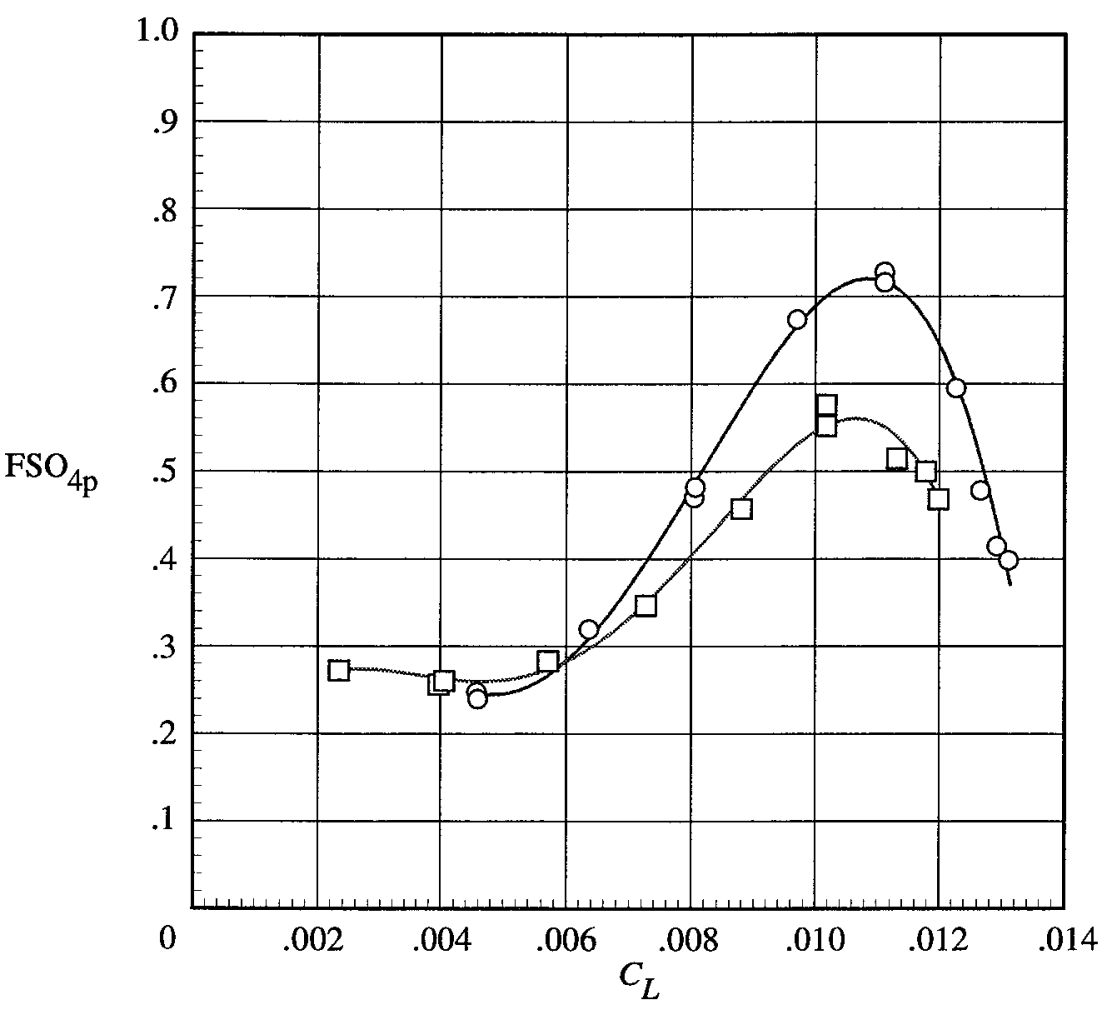

(c) $\alpha_{s}=0^{\circ} ; \mu=0.25$ and 0.26 .

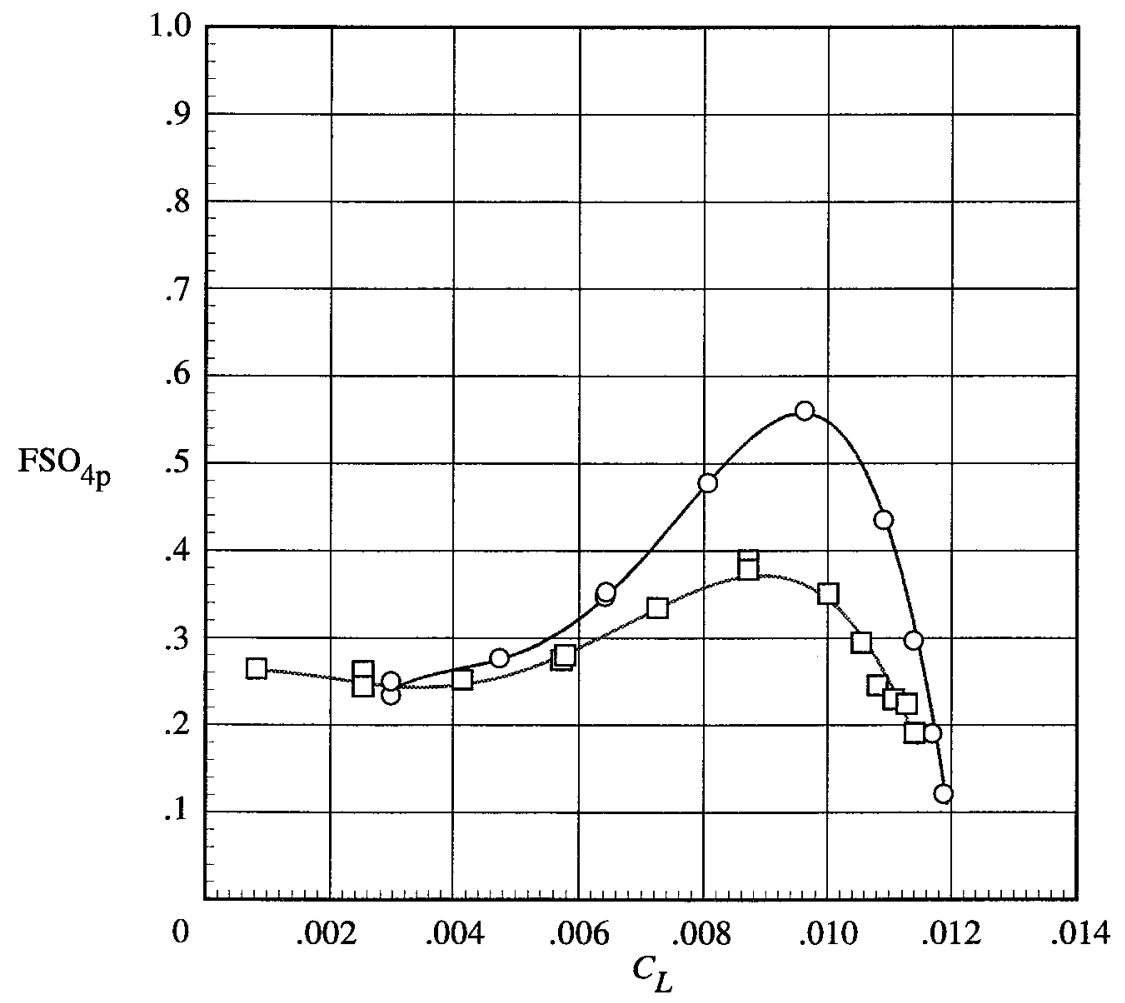

(d) $\alpha_{s}=-4^{\circ} ; \mu=0.25$ and 0.26 .

Figure 14. Continued.
O Baseline; $\mu=0.25$

$\square$ BERP type; $\mu=0.26$
O Baseline; $\mu=0.25$

$\square$ BERP type; $\mu=0.26$ 




O Baseline; $\mu=0.35$

$\square$ BERP type; $\mu=0.36$

(e) $\alpha_{s}=-2^{\circ} ; \mu=0.35$ and 0.36 .

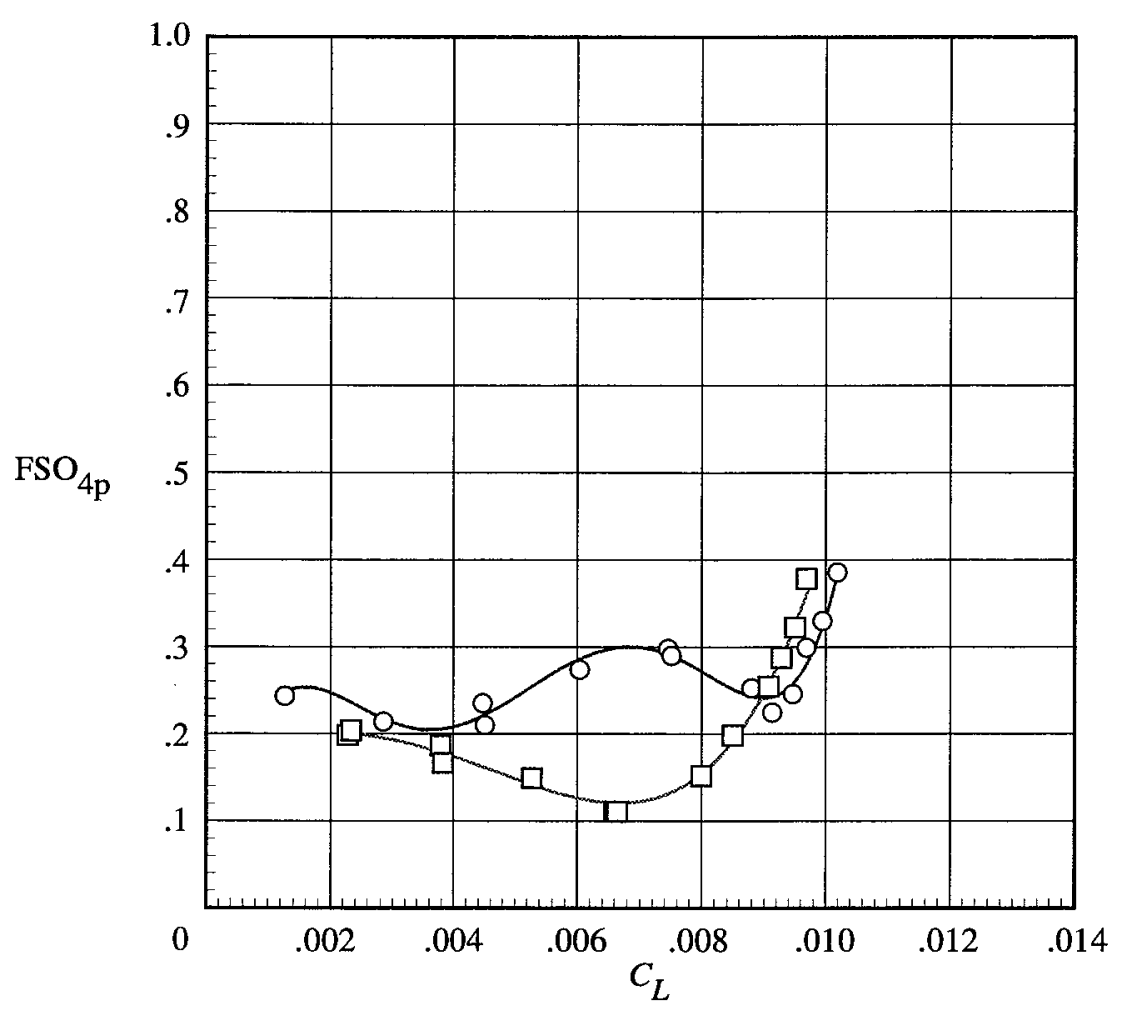

O Baseline; $\mu=0.35$

$\square$ BERP type; $\mu=0.35$

(f) $\alpha_{s}=-6^{\circ} ; \mu=0.35$.

Figure 14. Concluded. 


\begin{tabular}{|c|c|c|c|c|}
\hline \multicolumn{3}{|c|}{ REPORT DOCUMENTATION PAGE } & \multicolumn{2}{|r|}{$\begin{array}{l}\text { Form Approved } \\
\text { OMB No. 0704-0188 }\end{array}$} \\
\hline \multicolumn{5}{|c|}{$\begin{array}{l}\text { Public reporting burden for this collection of information is estimated to average } t \text { hour per response, including the time for reviewing instructions, searching existing data sources, } \\
\text { gathering and maintaining the data needed, and completing and reviewing the collection of information. Send comments regarding this burden estimate or any other aspect of this } \\
\text { collection of information, including suggestions for reducing this burden, to Washington Headquarters Services, Directorate for Information Operations and Reports, } 1215 \text { Jefferson } \\
\text { Davis Highway, Suite 1204, Arlington, VA 22202-4302, and to the Office of Management and Budget, Paperwork Reduction Project (0704-0188), Washington, DC 20503. }\end{array}$} \\
\hline 1. AGENCY USE ONLY (Leave blank) & $\begin{array}{l}\text { 2. REPORT DATE } \\
\text { May } 1997\end{array}$ & \multicolumn{3}{|c|}{$\begin{array}{l}\text { 3. REPORT TYPE AND DATES COVERED } \\
\text { Technical Memorandum }\end{array}$} \\
\hline \multicolumn{3}{|c|}{$\begin{array}{l}\text { 4. TITLE AND SUBTITLE } \\
\text { Performance and Vibratory Loads Data From a Wind-Tunnel Test of a Model } \\
\text { Helicopter Main-Rotor Blade With a Paddle-Type Tip }\end{array}$} & \multirow{2}{*}{\multicolumn{2}{|c|}{$\begin{array}{l}\text { 5. FUNDING NUMBERS } \\
\text { WU 505-63-36-02 } \\
\text { PR A5008 }\end{array}$}} \\
\hline \multicolumn{3}{|c|}{$\begin{array}{l}\text { 6. AUTHOA(S) } \\
\text { William T. Yeager, Jr., Kevin W. Noonan, Jeffrey D. Singleton, Matthew L. } \\
\text { Wilbur, and Paul H. Mirick }\end{array}$} & & \\
\hline \multicolumn{3}{|c|}{$\begin{array}{ll}\text { 7. PERFORMING ORGANIZATION NAME(S) AND ADDRESS(ES) } \\
\text { Vehicle Technology Center } & \text { Joint Research Program Office } \\
\text { U.S. Army Research Laboratory } & \text { Aeroflightdynamics Directorate } \\
\text { NASA Langley Research Center } & \text { U.S. Army Aviation and Troop Command } \\
\text { Hampton, VA 23681-0001 } & \text { NASA Langley Research Center } \\
& \text { Hampton, VA 23681-0001 }\end{array}$} & \multicolumn{2}{|c|}{$\begin{array}{l}\text { 8. PERFORMING ORGANIZATION } \\
\text { REPORT NUMBER } \\
\text { L-17558 }\end{array}$} \\
\hline \multicolumn{3}{|c|}{ 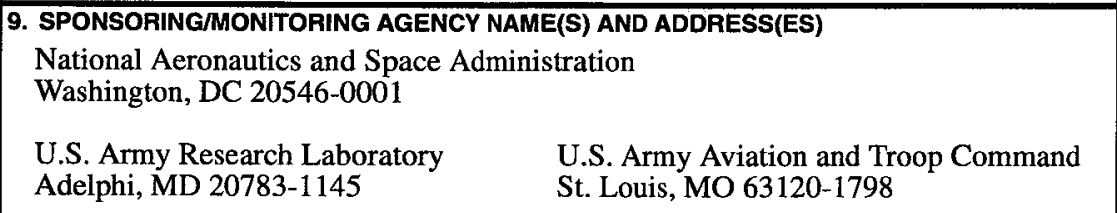 } & \multicolumn{2}{|c|}{$\begin{array}{l}\text { 10. SPONSORING/MONITORING } \\
\text { AGENCY REPORT NUMBER } \\
\text { NASA TM-4754 } \\
\text { ARL-TR-1283 } \\
\text { ATCOM TR-97-A-006 }\end{array}$} \\
\hline \multicolumn{5}{|c|}{$\begin{array}{l}\text { 11. SUPPLEMENTARY NOTES } \\
\text { Yeager, Singleton, Wilbur, and Mirick: Vehicle Technology Center, ARL, Langley Research Center, Hampton, VA; } \\
\text { Noonan: JRPO, Aeroflightdynamics Directorate, ATCOM, Langley Research Center, Hampton, VA. }\end{array}$} \\
\hline \multicolumn{3}{|c|}{$\begin{array}{l}\text { 12a. DISTRIBUTION/AVAILABILITY STATEMENT } \\
\text { Unclassified-Unlimited } \\
\text { Subject Category } 02 \\
\text { Availability: NASA CASI (301) 621-0390 }\end{array}$} & \multicolumn{2}{|c|}{ 12b. DISTRIBUTION CODE } \\
\hline \multicolumn{5}{|l|}{$\begin{array}{l}\text { baseline main-rotor blade and } \\
\text { were compared with regard to } \\
\text { loads. Data were obtained in } \\
\text { Results indicate that the padd } \\
\text { Pitch-link oscillatory loads for } \\
\text { fixed-system loads are general }\end{array}$} \\
\hline \multirow{2}{*}{$\begin{array}{l}\text { 14. SUBJECT TERMS } \\
\text { Helicopters; Model rotor } \\
\text { Blade tip geometry }\end{array}$} & \multirow{2}{*}{ testing; Helicopter rotor } & \multirow{2}{*}{\multicolumn{2}{|c|}{ performance; Blade loads; }} & $\begin{array}{c}\text { 15. NUMBER OF PAGES } \\
24\end{array}$ \\
\hline & & & & $\begin{array}{r}\text { 16. PRICE CODE } \\
\text { A03 }\end{array}$ \\
\hline $\begin{array}{l}\text { 17. SECURITY CLASSIFICATION } \\
\text { OF REPORT } \\
\text { Unclassified }\end{array}$ & $\begin{array}{l}\text { 18. SECURITY CLASSIFICATION } \\
\text { OF THIS PAGE } \\
\text { Unclassified }\end{array}$ & $\begin{array}{l}\text { 19. SECURITY CLASSIF } \\
\text { OF ABSTRACT } \\
\text { Unclassified }\end{array}$ & FICATION & $\begin{array}{l}\text { 20. LIMITATION } \\
\text { OF ABSTRACT }\end{array}$ \\
\hline NSN 7540-01-280-5500 & & & & $\begin{array}{l}\text { Standard Form } 298 \text { (Rev. 2-89) } \\
\text { Prescribed by ANSI Std. Z39-18 } \\
298-102\end{array}$ \\
\hline
\end{tabular}

